\title{
A Methodological Approach for the Study of Domes
}

\author{
Carlo Bianchini ${ }^{1}$
}

Accepted: 16 September 2020 / Published online: 2 October 2020

(c) The Author(s) 2020

\begin{abstract}
Domes still represents a prickly subject, large dimensions coupled with a limited accessibility making their study difficult and time-consuming. Although throughout history this problem has been tackled in different ways, relevant methodological and operational issues have until now limited the success of these efforts. Digital technologies have radically changed this scenario. 3D active and passive capturing systems currently allow for a dense and accurate surveying while modelling software provides powerful tools to build virtual counterparts of surfaces and to investigate their geometric properties. The aim of this paper is to present three different projects developed by a research group in the Department of History, Representation and Restoration of Architecture-Sapienza University of Rome. Based on their results, the group has set up and tested a protocol that can guide users from acquisition through modelling and, finally, to the reading of the geometric properties of domes.
\end{abstract}

Keywords Domes · Hagia Sophia $\cdot$ San Carlo ai Catinari $\cdot$ St. Peter's · Survey

\section{Introduction}

The study of domes still represents a thorny subject. In fact, large dimensions coupled with a limited accessibility make the study of their shapes and geometry a traditionally difficult task (Rondelet 1802-17; Leroy 1845). Although throughout history this problem has been tackled in different ways (Letaroully 1840-55; Emerson and Van Nice 1943; Dorffner et al. 2000; Hidaka and Satō 2004), relevant methodological and operational issues have until now limited the success of these efforts.

Digital technologies have radically changed this scenario. On one hand, 3D active capturing systems (Light Detection and Ranging, LIDAR) and passive ones (Structure from Motion, SfM) currently allow for a dense and accurate surveying

Carlo Bianchini

Carlo.bianchini@uniroma1.it

1 Department of History, Representation and Restoration of Architecture, Sapienza Università di Roma, Piazza Borghese, 9, Rome, Italy 
of surfaces (Bianchini and Russo 2018); on the other, modelling software provides powerful tools to build virtual counterparts (3D models) of these surfaces as well as to investigate their geometric properties (Migliari 2008).

The aim of this paper is to present three different projects developed in the last decade by a research group belonging to the Department of History, Representation and Restoration of Architecture (DSDRA)—Sapienza University of Rome. Based on the results of these activities, our group has set up and tested a protocol that can guide users from the acquisition phase through the modelling and, eventually, to the reading of the geometric properties of domes. However, this chain of activities must not be regarded as a mere application of different technologies but instead as the operational display of a rigorous scientific methodology (Bianchini 2014) that guides the construction of a 'knowledge system' suitable for collecting, interpreting and storing information. The components of this system are of various types: first quantitative (essentially resulting from surveying operations), but also qualitative. While the former can be channelled through a rigorous scientific approach, the latter mainly draw on the investigator's subjective sensitivity and interpretative skill. Nonetheless, this last is often a key ingredient for achieving levels of understanding that are denied to simple measurement (Ribichini 2015; Chiavoni 2018; Inglese et al. 2019).

This duality between measuring and interpretation in the study of built artefacts has also had a strong impact on the hypothesis discussed and the result presented in this paper. Even if very briefly, we cannot afford to bypass some of the epistemological implications of this approach, namely to reference the qualitative component (interpretation) to the concept of irrefutability in the sense proposed by Karl Popper (1963). On the other hand, we must reference the quantitative one (measuring) to the bimillennial disciplinary context of survey, certainly one of the most powerful tools developed by scholars (archaeologist, architects, historians, etc.) that 'distinguish those who know from those who remain on the surface, even so-called "cultured", of knowledge'. ${ }^{1}$ It actually implies the idea of measurement, that is to say, the possibility of turning into quantity some qualities of the studied phenomenon (in this case an artefact, a building, a site, etc.) by using the ratio between the measured quantity and an appropriate unit of measure. Thanks to this method, we can build the model of the complex phenomenon we are investigating as a simplified version of the original.

\section{The Epistemological Framework}

Quite apart from the theoretical framework, the application of this approach to built artefacts, and especially to domes, strictly depends on the available measurement technologies. For centuries, the limited possibilities offered by instruments have restricted the number of measurable points. Therefore, any survey campaign

\footnotetext{
1 Sanpaolesi (1973: 62): ...distingue i conoscitori da coloro che restano alla superficie, anche cosiddetta colta, della conoscenza.
} 


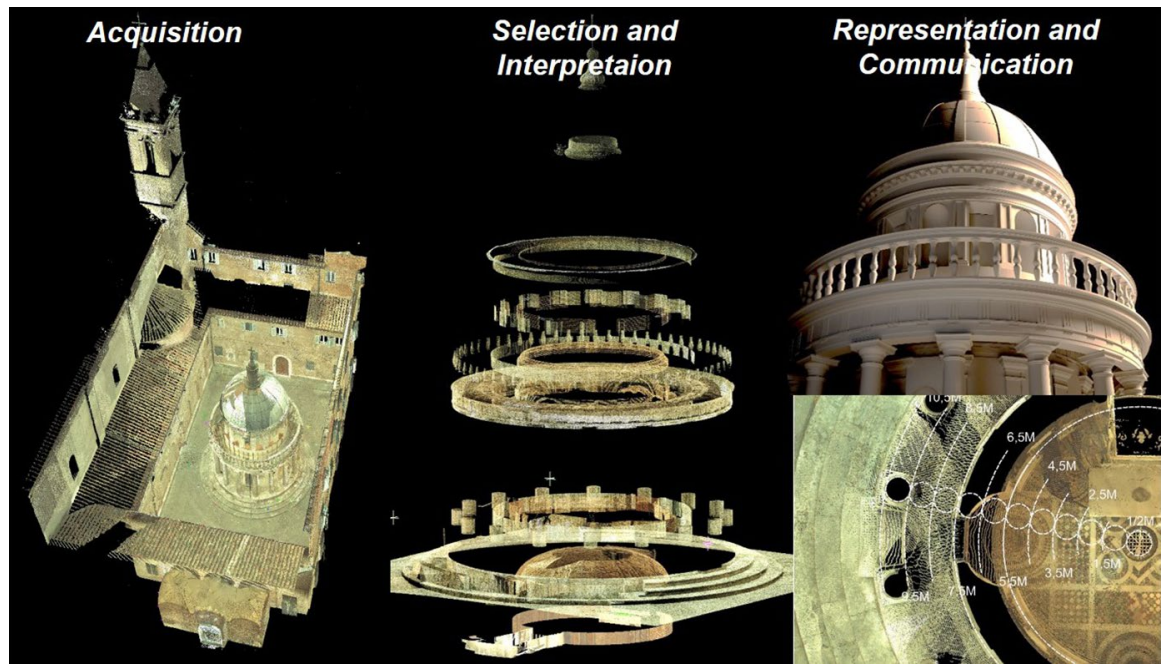

Fig. 1 The phases of the survey workflow

required a preliminary accurate design in order to select and then acquire (measure) the really significant points.

In recent decades, instead, all 3D capturing technologies (LIDAR, SfM) have somehow inverted this order so that selection nowadays follows acquisition. Therefore, the term 'survey' refers not only to the measuring campaign, but also to a very structured process that leads to the construction of $2 \mathrm{D}$ or $3 \mathrm{D}$ models starting from a real object (Docci et al. 2011; Bianchini 2012; Gaiani 2012). This workflow can be broken down into several different tasks of which, certainly, the acquisition phase ${ }^{2}$ represents the first step. All those that follow-namely selection, interpretation and representation of the acquired data-actually lead to $2 \mathrm{D}$ and $3 \mathrm{D}$ models that somehow concur in adding to our knowledge of the phenomenon, i.e., the built artefacts we are investigating (Fig. 1).

Referring to the traditional survey approach, the tasks of acquisition, selection, interpretation and representation of data are genetically tangled together. Massive acquisition technologies have instead separated all steps: capturing has become the only onsite activity, while selection, interpretation, and representation of data are now carried out later and generally offsite (Bianchini 2014). This last remark is in our opinion very valuable, because it allows for a revisiting of the entire matter in the light of the scientific method, also putting the survey process to the test of Karl Popper's "principle of falsifiability", still the benchmark for evaluating scientific theories. ${ }^{3}$ The capturing phase seems to be highly compatible with the validation

\footnotetext{
${ }^{2}$ In the literature we also find the terms 'surveying', 'measuring', and 'capturing' for this phase.

3 With this principle, Popper sought to resolve the impasse that arose between Russell's fruitless attempts to construct "complete" logical deductive systems, and the cataclysm that swept through epistemological thinking following Kurt Gödel's proof of the Incompleteness Theorem. Popper, well aware of the inherent inadequacy of the tools that human beings have for cognizing reality and that, in the final analysis, it is substantially impossible to provide "positive" proof that any given statement is
} 
workflow consolidated within the scientific community. Instead, selection, interpretation and representation cannot satisfy these requirements and must thus always be considered subjective and irrefutable in the terms set out by Popper.

However, it is within the selection and interpretation phases that the model is produced. It is mainly a geometric model, i.e., a simplified reading of the objective multi-dimensional complexity referring to its geometric essence made of points, lines and surfaces. The real object and its virtual substitute are thus bound together by a biunivocal correspondence that can be used to simulate different operations as if they were made directly on the object itself.

From a strictly epistemological point of view, such a model can be considered the result of a selection carried out by a subject aiming at extracting some of the potentially infinite information embedded into an object. The selected data, though, are not the result of a random or automatic processing. On the contrary, they are the result of an interpretation, a subjective reading that strictly complies with rules established by the subject himself/herself. In other words, starting from the selected set of data, we always tend to demonstrate a hypothesis we have formulated beforehand even if subconsciously.

However, at this stage the model produced is, so to speak, for personal use only, existing mainly in the mind of the subject and often incoherently on scattered supports (such as sketches on napkins). Hence, representation is the method to transform this personal model so to make it understandable to others. This phase actually translates the "raw" model into a shareable one, applying a codification that relies on descriptive geometry and in particular on the science of representation (Docci and Migliari 1992).

This whole process has been traditionally rooted in the following principles:

- human beings have an ability, innate or acquired, to conceive the qualities of physical space;

- of the $n$ qualities of a physical space, the geometric qualities optimize the operations of interaction between subject and space;

- space can be effectively manipulated and modified thanks to the correspondence between the real object and its geometric abstraction (geometric model);

- the geometric model, through the process of representation becomes a 2D graphic model or a 3D virtual model.

While for the 2D graphic models we can refer to the millennia-old tradition of drawing (Docci 1997), the 3D virtual models are only the 25-year-old products of the so-called "digital revolution" and of its wide "bundle" of hardware and software

Footnote 3 (continued)

true, shifts the centre of gravity of knowledge from proving that something is true to showing that it is false. For Popper, a theory is scientific only if it is possible to devise experiments that demonstrate its inadequacy, i.e., that refute it as false. This approach has been revealed as highly profitable in terms of advancing of knowledge: if a theory withstands an attempt of falsification, it will be stronger, more general and thus closer to the truth; conversely, if the attempt succeeds, an aspect will be revealed that the theory was unable to explain, and a new and stimulating line of research will thus be opened up. 


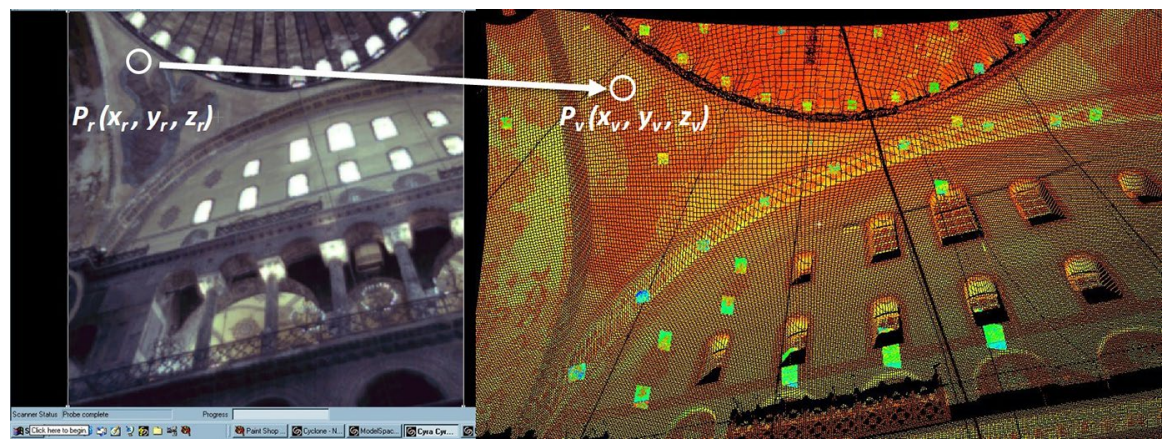

Fig. 2 Correspondence between physical and virtual space

tools that nowadays allow for an actual interaction between our real world and its virtual version.

Digital modelling systems represent a real novelty in comparison with the traditional graphic workflow: while for the 2D graphic models the process establishes a biunivocal correspondence between the object and its graphic representation by means of projection and section operations, 3D modelling software creates instead an entire 3D virtual space.

Therefore, more than producing a mere representation of the object, any 3D modelling software provides the possibility to interact with a digital environment that, initially empty, is step by step populated by elements that together build a virtual replica of the object.

This process establishes a direct correspondence between the physical and the virtual space: to each material point $\mathrm{P}_{\mathrm{r}}^{4}$ identified by its coordinates $\mathrm{x}_{\mathrm{r}}, \mathrm{y}_{\mathrm{r}}, \mathrm{z}_{\mathrm{r}}$ in the real space corresponds to a virtual point $\mathrm{P}_{\mathrm{v}}$ univocally identified by the Cartesian triplet $\mathrm{x}_{\mathrm{v}}, \mathrm{y}_{\mathrm{v}}, \mathrm{z}_{\mathrm{v}}$ (Fig. 2).

Consequently, the digital environment created by 3D modelling software provides an actual spatial framework for all the subsequent constructions.

Therefore, the relevance of 2D/3D models exceeds the mere production of their final and perhaps more evident outputs (drawings, images). Their vocation is instead exquisitely heuristic, providing 'the way of recognizing, from an exact description, the forms of bodies, and of deducing from them all the truths which result both from their form and from their respective positions" and the possibility "... to realize in all directions, at small scale on paper, or in large scale in an area or on a plaster, the measurements and shapes of a part of a building". 6

\footnotetext{
${ }^{4}$ With the term material point we refer to the small objectual area that is synthetized in the model by a single geometric point. For instance, if we consider a 3D laser scanner, the dimensions of this area span from some millimeters to few tenths of a millimeter depending on the instrumental resolution.

5 Monge (1811: 1): ...la manière de reconnaître, d'après une description exacte, les formes des corps, et d'en déduire toutes les vérités qui résultent et de leur forme et de leurs positions respectives...

${ }^{6}$ Rondelet (1802-1817: Tome II, 75): ....se rendre compte dans tous les sens, en petit sur le papier, ou en grand sur une aire ou un enduit, des mesures et des formes d'une partie d'édifice.
} 


\section{Methodology}

The theoretical background discussed so far actually represents the backbone of the methodology we have applied to some of the most relevant domed structures in the world.

As mentioned in the very first lines of this paper, domes are difficult to investigate. Throughout history, many methods have been applied to measure their surfaces and to assess their geometry and shape. Despite these efforts, some "intrinsic" constraints have always limited the success of these tasks: on one hand, the surveying campaigns used to produce small and inaccurate datasets; on the other, the tools for the investigation of surfaces were rich from a theoretical standpoint but very poor from an operational one. The combination of the two has generally prevented the achievement of reliable results. Besides, domes are quite difficult even to reach: their large dimension and troublesome position in the fabric is very often coupled with a scant accessibility of their upper levels that deeply affects the implementation of direct surveying procedures. Topographic measurements are also limited by the same logistic problems but, accepting the adoption of a very time-comsuming workflow, they have represented a significant jump forward in the study of domes, as witnessed by the work on Hagia Sophia in Istanbul (Emerson and Van Nice 1943; Mainstone 1988).

Stereophotogrammetry (Fondelli 1992) seemed for a while able to solve many of these issues. This technique allows for the construction of a "virtual model" of an object using a coordinated pair of photographic shots. Complex hardware (now obsolete) operated by skilled users could lead to the measuring and drawing in a CAD 3D space of single points, lines and polylines, simply by exploring the virtual model visually. However, the clear improvements introduced by stereophotogrammetry in terms of operational capabilities and accuracy were differently applicable to domes shapes. Due to the dependence on the coverage and position of photographic acquisitions, the accuracy of measurement was generally high in correspondence of the keystone, but dramatically decreasing in moving towards the level of the springing (Bianchini and Paolini 2003).

Instead, LIDAR and SfM systems in the multiple configurations that we can observe nowadays (stable, portable, flying, diving) produce dense and accurate datasets in the form of point clouds. Yet, this "capturing power" would have been actually irrelevant without the parallel development of 3D modelling systems that grants us the possibility not only to do better what we used to do, but above all to do what was simply impossible before.

The samples presented in sections that follow (the domes of the Hagia Sophia in Istanbul, San Carlo ai Catinari in Rome, and St. Peter's Basilica in the Vatican City) intend to present both a demonstrator of the workflow discussed so far and some interesting results in the geometric study of surfaces. 


\section{Hagia Sophia in Istanbul}

'Glory to God, who deemed me worthy to finish this construction. O Solomon, thus have I prevailed over you.' With these words Emperor Justinian, together with the Patriarch inaugurated Hagia Sophia church on 27 December 537 AD, only 5 years after the laying of the first stone.

Hagia Sophia is undoubtedly the product of the Emperor's will: inspired by Justinian's new-found faith, this unprecedented construction is also more prosaically driven by the political need to explicitly embody in this building his imperial power. That is why the Emperor invested enormous resources and personal energy in this endeavour. He chose carefully his team of designers (the Greek mathematician and architect Anthemius of Tralles assisted by Isidorus the Elder of Miletus) but he personally supervised the work imposing strict working conditions. Ten thousand workers, divided into two competing, "militarized" teams, accomplished the construction task in an unprecedented time. This speed, however, undermined the stability of the building from the very beginning and determined a first major collapse of its dome some 20 years after the dedication of the church. A new covering, less hollow than Antemius', was then rebuilt by Isidorus the Younger of Miletus.

The overall design of Hagia Sophia is based on a huge square with sides of approximately $62 \mathrm{~m}$. Another smaller, concentric square (side of about $31 \mathrm{~m}$, or 100 Byzantine feet) is contoured at its corners by four large piers that support the central dome. The transition from square to the springing circumference of the dome is solved by inserting four spherical pendentives, another great invention of Antemius, that will become an absolute paradigm of Western architecture. Transformed in a mosque by Mehmed the Conqueror after Constantinople fall in 1453, at the beginning of the twentieth century Ataturk changed its function into a museum but, very recently, it has been re-converted into a mosque.

The huge dome that soars above its central space, certainly its most remarkable element, has also proven over time to be its Achilles' heel. The irregular surface we can currently observe visiting the monument is thus the result of the layered and often incoherent reconstructions that followed the three major collapses that occurred over time.

We approached the study of this structure basing on a general point cloud of about 100 million points ${ }^{7}$ (Fig. 3), spanning from a minimum density of $4 \times 4 \mathrm{~cm}$ to a maximum of $2 \times 2 \mathrm{~mm}$. The processing of this dataset allowed for the construction

\footnotetext{
7 It is worth underlining that the point cloud analyzed in this study is the product of a "scientific" joint venture between our group from DSDRA and the team from the Institut für Kunstgeschichte der Universität Bern led by Volker Hoffmann and Nikolaos Theocharis (2016). As a quarter of the central area of Hagia Sophia is almost permanently occupied by a huge scaffolding used for the restoration of the dome, which prevents a complete capturing of its intrados, we decided to share our "individual" clouds in order to improve the quality and quantity of available data. Although we can read only very few points in a relevant portion of the dome (only those captured by the beams filtering through the scaffolding), this unconventional exchange of data is, in our opinion, a valuable good practice in the study of complex structures.
} 


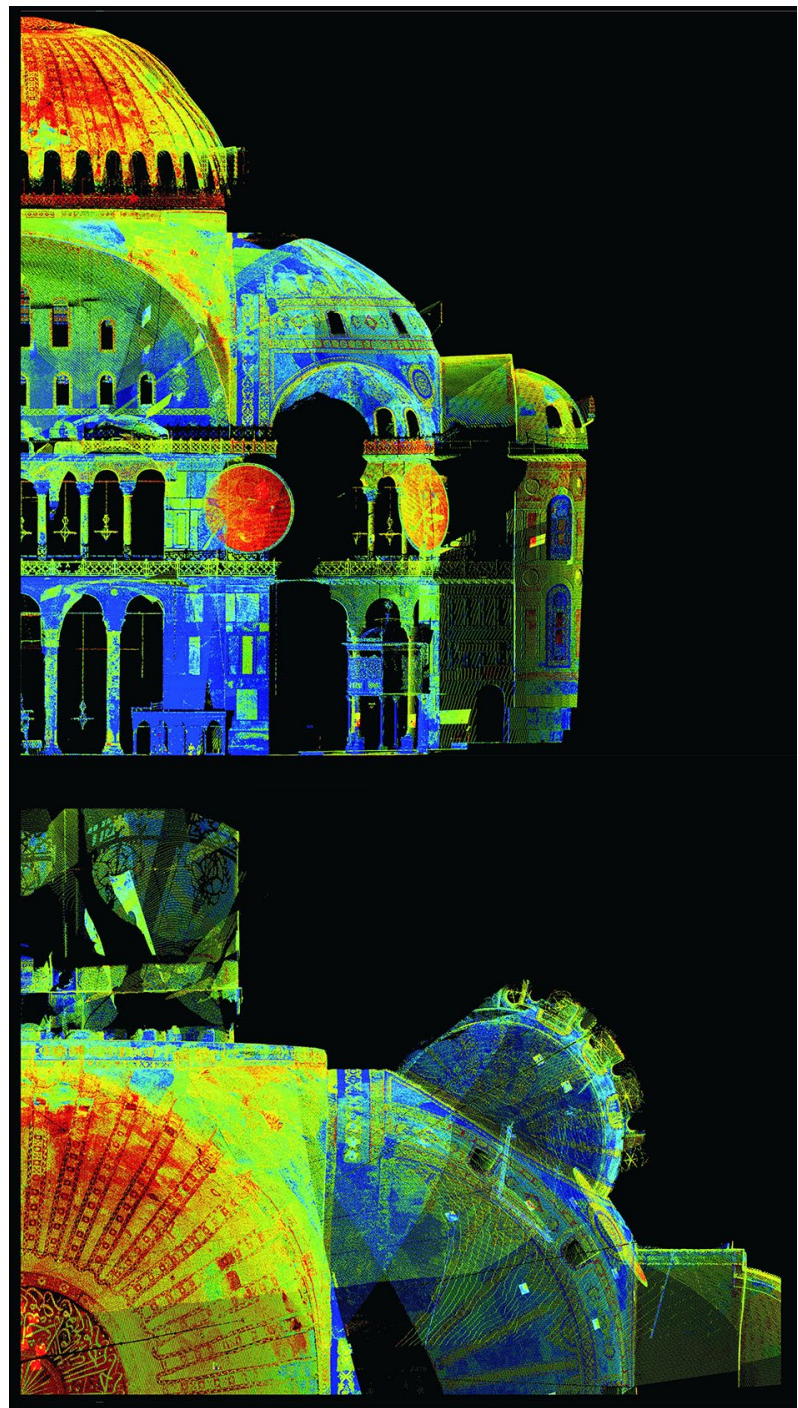

Fig. 3 Hagia Sophia's general point cloud

of a number of 2D and 3D models aimed at assessing the dimensions and alignments of the structures bearing the dome.

We focused, in particular, on the four main piers, on the two large arches located east and west along the main axis of the nave and, finally, on the pair of arches and subarches facing respectively north and south.

The first phase investigated the shape of the arches bearing the dome along the east and west axis. We started by sectioning the point cloud along ten vertical planes perpendicular to the axis of each arch (Fig. 4). The set of 3D points 


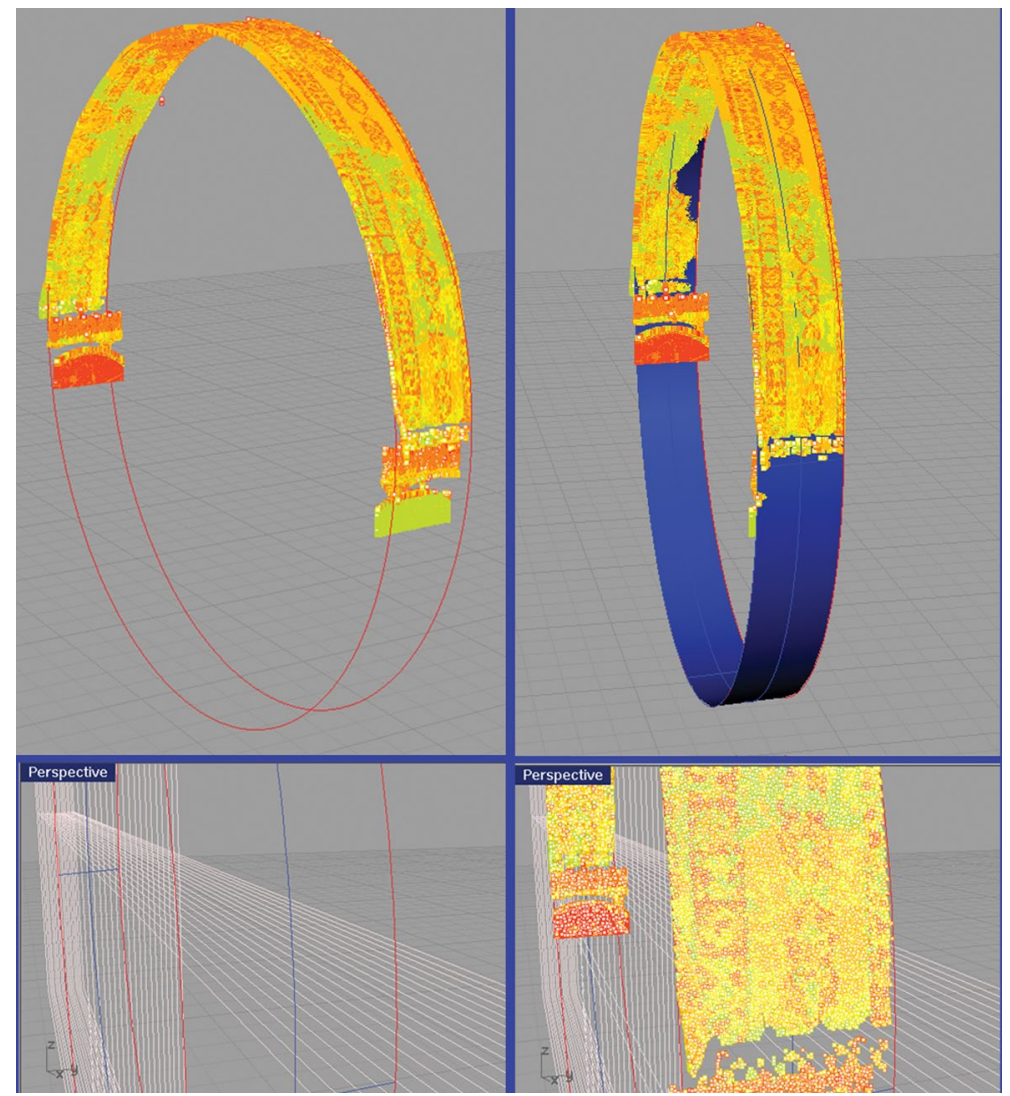

Fig. 4 Study of the geometry of the arches bearing the dome

intersected along each plane was then interpolated in order to trace the best fitting circumference to assume as the most probable profile used in the construction.

This operation revealed an unexpected geometry: the intrados of neither east nor west arches correspond to a cylindrical surface, but are instead portions of a truncated circular cone. The outer and inner semicircles delimiting each arch have been built using different radii: the largest, facing the dome, measure $16.81 \mathrm{~m}$ while the other is $16.50 \mathrm{~m}$ long (Fig. 5).

The reason for this difference is not clear; it is too great and regular to be unintentional but still too small to be noted without measuring. Nevertheless, it could be explained either in terms of "smoothing" the too sharp transition between the intrados of the arches and the dome, or as an optical correction conceived by the designer.

Other interesting findings refer to the north and south walls, both clearly deformed over time by the thrust of the dome. The north wall is bending considerably outwards: $66 \mathrm{~cm}$ in the portion between the ground floor and the 
Fig. 5 The shape of the intrados of the arches

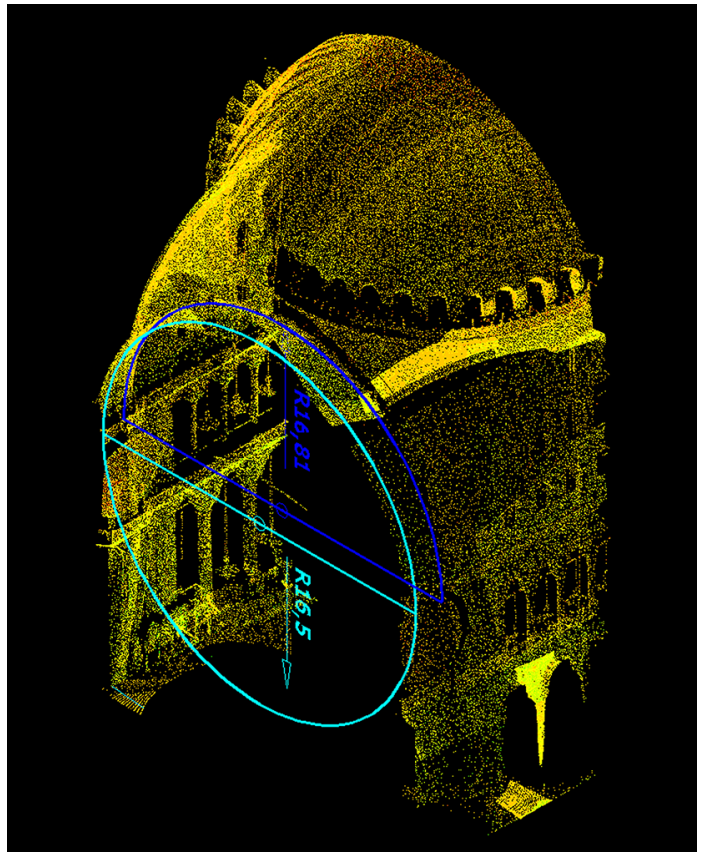

upper cornice of the matroneum, reaching a total incline of approximately $1 \mathrm{~m}$ just below the springing level of the dome.

The dome is actually the element that has been subjected to the greatest transformations. Originally designed by Anthemius of Tralles as a very hollow portion of a sphere, it collapsed for a combination of reasons in 558 AD. Rebuilt by Isidore of Miletus, again based upon a sphere but with a much higher profile, the dome suffered two other partial collapses in 989 and 1346 caused by major earthquakes. The structure we see today is then the result of the layering of these reconstructions visibly carried out in an approximate way by a work force not skilled enough to handle properly the problem.

Our study started by sectioning the point cloud of the dome using 60 horizontal planes at $25 \mathrm{~cm}$ intervals (Fig. 6). We then selected 45 of them as representative of the most evident deformations. Likewise, we constructed a number of radial sections passing through the vertical axis of the sphere and the middle of the ribs that compose the intrados of the dome (Fig. 7).

This set of horizontal and vertical curves showed the location and degree of unevenness of the surface: from the unmistakable re-stitching along the north-east diagonal, to the deformations in the interval between 53.5 and $49 \mathrm{~m}$ above ground level. Finally, other remarkable differences were found at the level of the springing of the dome along the east and southeast directions.

Ancient Byzantine building techniques undoubtedly played a key role in both the construction of this masterpiece of Western architecture but also in creating its main weak points. The hollow shape of the first two domes (and their consequent huge thrust outwards) not only affected the dome's stability, but also 

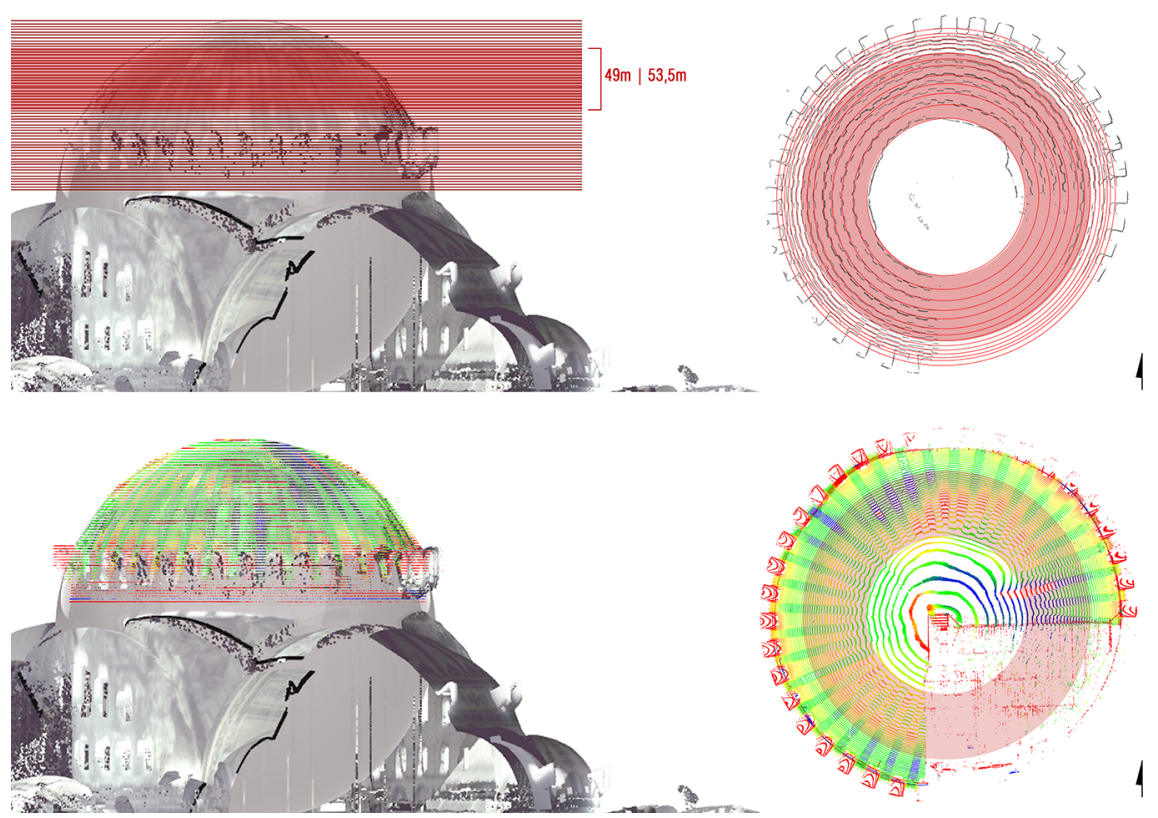

Fig. 6 The 2D study of Hagia Sophia dome: horizontal sectioning

undermined the solidity of the four main piers bearing the covering. The building phase itself, too quick to ensure the correct curing of the masonry, decreased on one hand the bearing capacity of the piers (and walls too) while on the other it caused important settling already evident during the construction.

In spite of the fact that the piers were made of solid stone blocks up to the level of the matroneum, still their deformation is indeed quite evident: the thrust of the east and west transversal arches made the piers lean outwards, widening them at the level of the springing by approximately $60 \mathrm{~cm}$ (Fig. 8).

All these conclusions belong to the "to do better what we used to do" class; in other words we have taken advantage of traditional 2D graphic models, as many other scholars have done for a long time (Emerson and Van Nice 1943; Sanpaolesi 1978; Mainstone 1988; Dorffner et al. 2000; Hidaka and Sato 2004). It is time now to shift to the "to do what simply was impossible before" class, namely to show the results of our 3D investigation (Bianchini and Paolini 2003; Docci 2003; Hoffmann and Theocharis 2016).

The first question we addressed was the reconstruction of the original shape of the dome, obviously not Anthemius' sphere (lost forever) but instead that of Isodore. Working directly on the $3 \mathrm{D}$ point cloud, we decided to search for the spherical surface best fitting our point cloud. However, taking into account the actual "umbrella" shape of the intrados, we choose to build two different spheres: one interpolating the points lying on the inner ribs, the other considering those belonging to the outer sails (Fig. 9). 
Fig. 7 The 2D study of Hagia Sophia dome: vertical sectioning

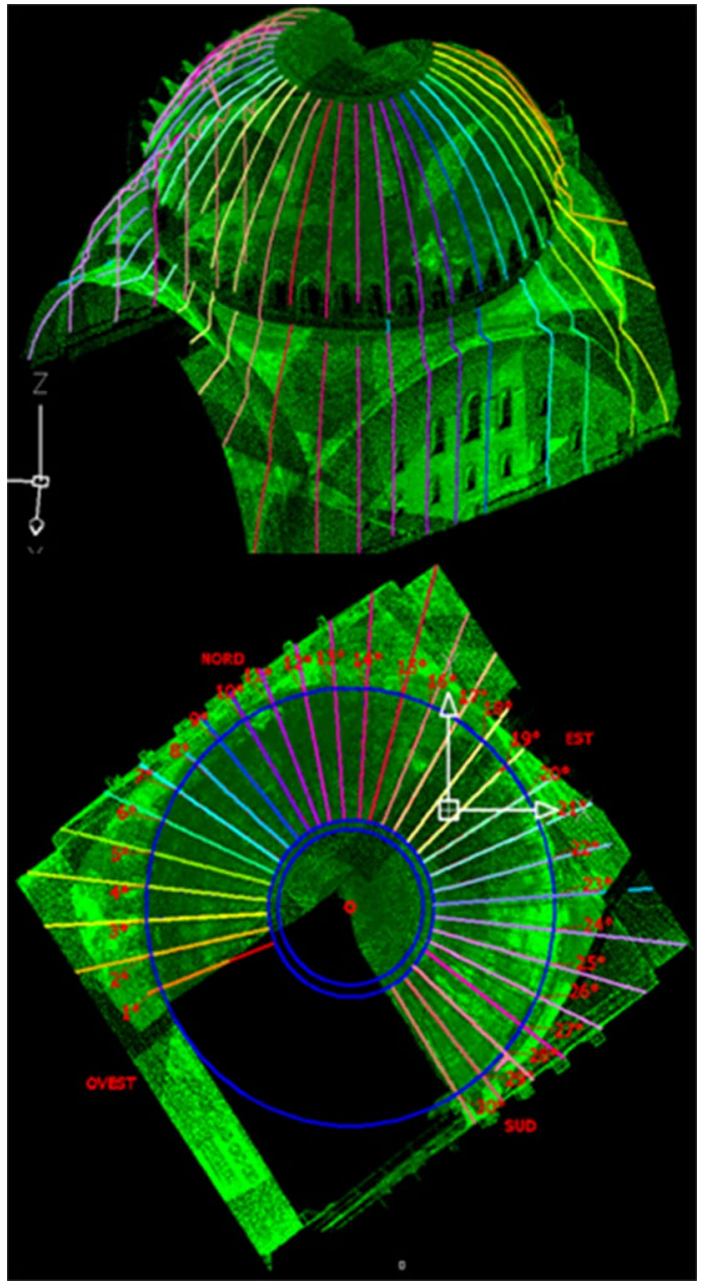

In the first case we selected a set of almost 430,000 points that led to a sphere with a radius of $16.62 \mathrm{~m}$, while in the second the points chosen were about 380,000 and the radius of the generated sphere was of $17.00 \mathrm{~m}$. Assuming the springing plane of the dome at $41.18 \mathrm{~m}$ from ground level, the distance between this plane and the spheres's centers were respectively of $1.85 \mathrm{~m}$ and $2.15 \mathrm{~m}$. Finally, the centres were displaced $0.33 \mathrm{~m}$ one from the other and approximately aligned with the top of the arches bearing the dome (Figs. 10, 11).

In this framework, we could assume as the "ideal" sphere the average one derived from the combination of the previous two. This surface shows the following features: radius $=16.81(54$ Byzantine feet $\pm 4 \mathrm{~cm})$; distance of the centre from the springing plane $=2.00 \mathrm{~m}$. It is interesting to note that the radius of this sphere actually coincides with that of the great arches we discussed above. However, without overestimating the value of this coincidence (too many "subjective" choices 
Fig. 8 The 2D study of Hagia Sophia's great walls

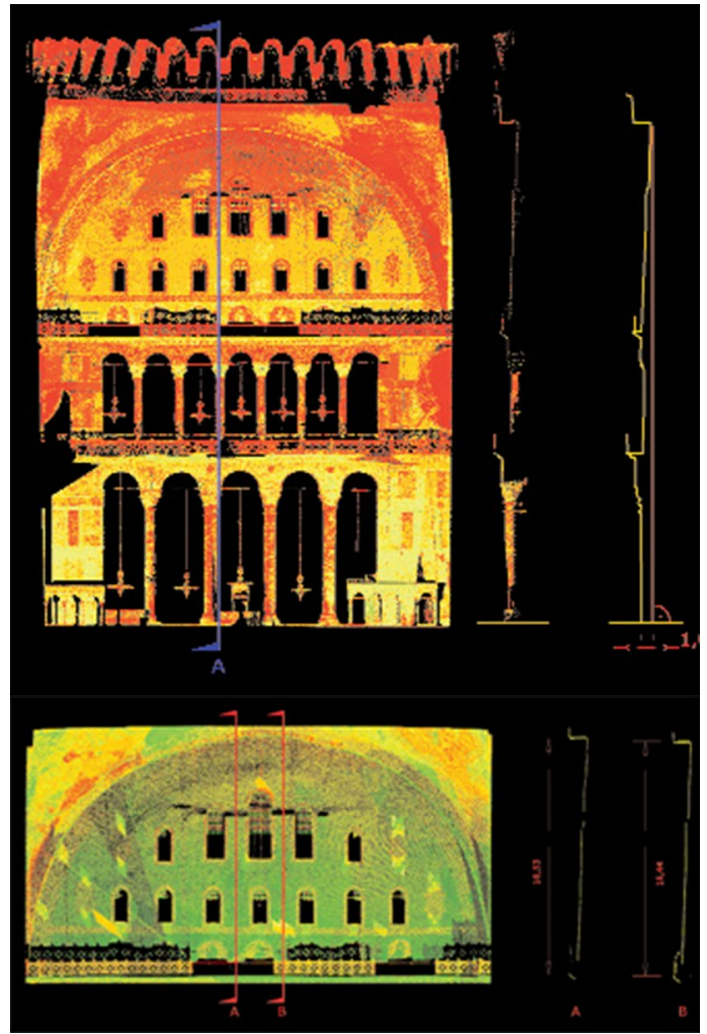

INNER RIBS OVERLAPPING

Radius $=16,62 \mathrm{~m}$, RMS (Root Mean Square) of 0,0926

Coordinates of the sphere center: $x=-7.371222 ; y=-6.969484$ $z=37.823727$

Coordinates of the sphere center: $x=-7.469120 ; y=-7.082422$ $z=37.529472$
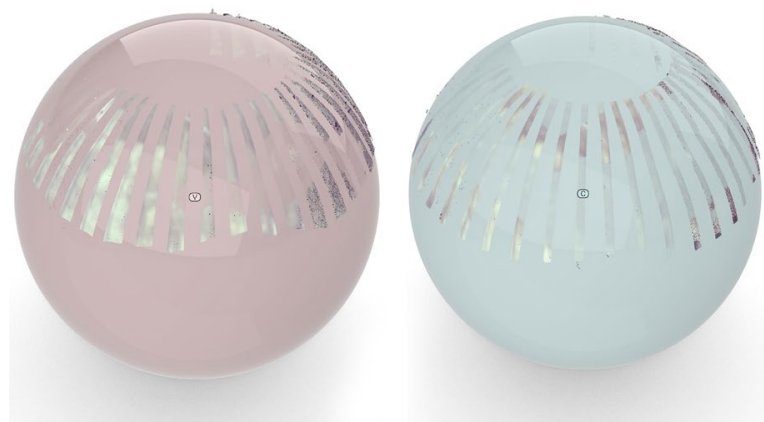

OVERLAPPING

Linear distance between the two centers: $33 \mathrm{~cm}$

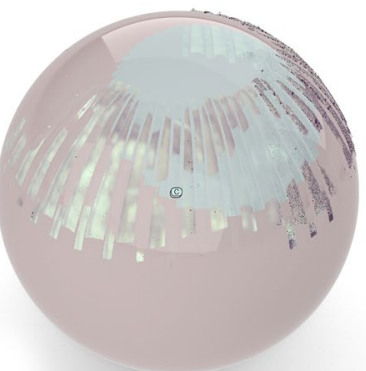

Fig. 9 The search for the best-fitting spheres of sails and ribs

to become a real proof of anything), it nonetheless suggests again a very refined (and overall simple) proportional control set up by the designers at the very beginning of this huge project. Furthermore, it also evokes more technical matters directly connected with the construction process in terms of the reutilization for the upper 


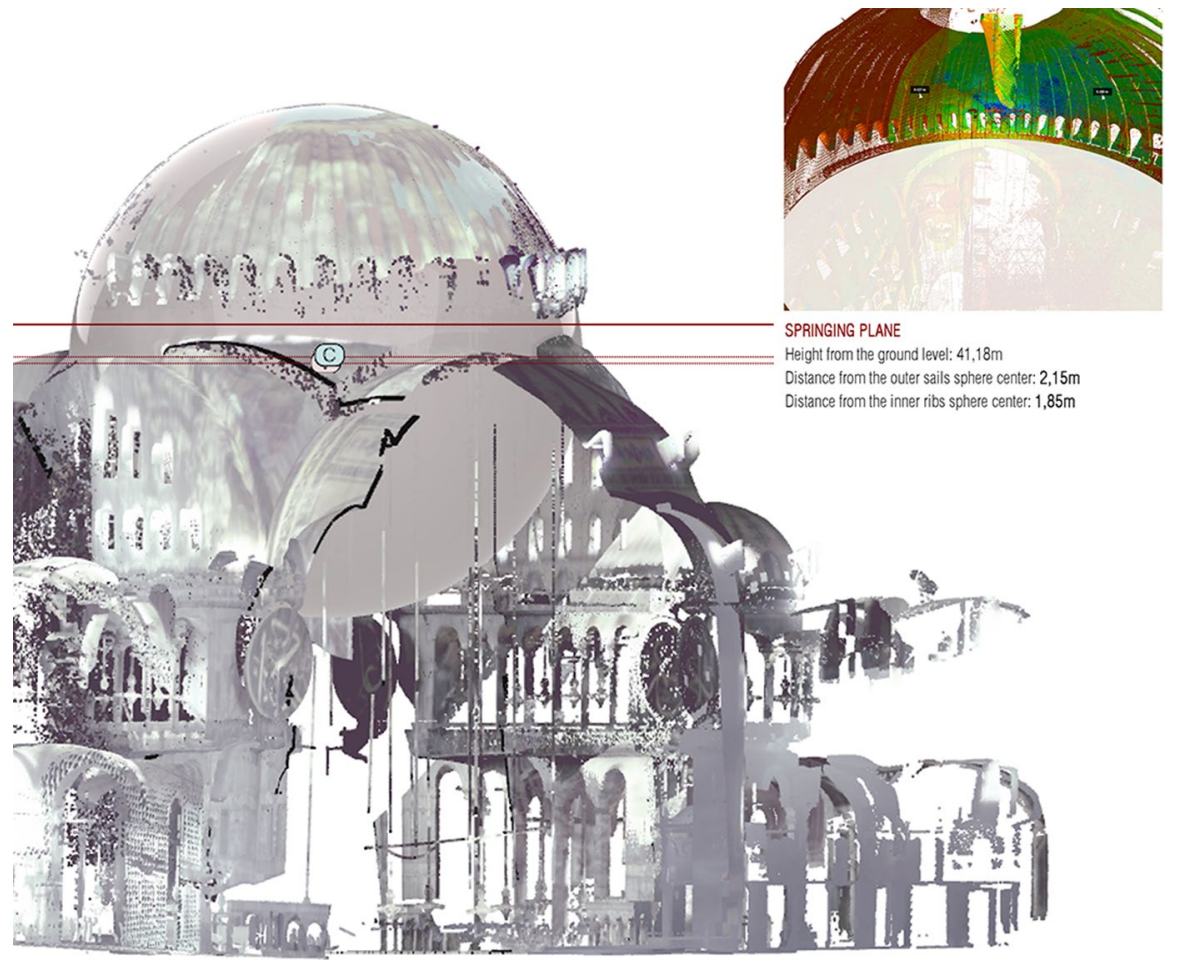

Fig. 10 Hagia Sophia ideal sphere: comparison between the ribs and sails interpolated surfaces

dome of the provisional structures (such as centrings) used for the lower arches. The circumference at the springing of this spherical dome measures $104.81 \mathrm{~m}$ and has a diameter of $33.38 \mathrm{~m}$ (106 Byzantine feet).

We then adopted this interpolated shape as a benchmark for making a comparison between the "ideal" geometry of Hagia Sophia's dome and its actual configuration. We could thus verify that the circumference at the springing has deformed into an irregular oval with the east-west diameter measuring $32.46 \mathrm{~m}$ while the north-south is $31.65 \mathrm{~m}$ long (Fig. 12). Many remarkable offsets between the ideal line and the surveyed profile concentrate along the north-south direction perpendicular to the main axis of the building. This fact is probably due to the different degrees of rigidity of the bearing structures. The semi-domes coupled to the east-west arches seem to have balanced the thrust of the dome more efficiently than the simple arches enclosing the north and south walls.

As a result, many ribs on the intrados of the dome are presently crooked (in some points by up to $80-100 \mathrm{~cm}$ ) with deformations that concentrate in two directions, spanning some $45^{\circ}$ on both sides of the main east-west axis. This configuration matches quite well with the documented reconstruction of approximately one quarter of the dome after its collapse in 1346 (Fig. 13).

The final step of this 3D analysis was the reconstruction of a model that could represent the actual geometry of the intrados. On the basis of all sections made and, 


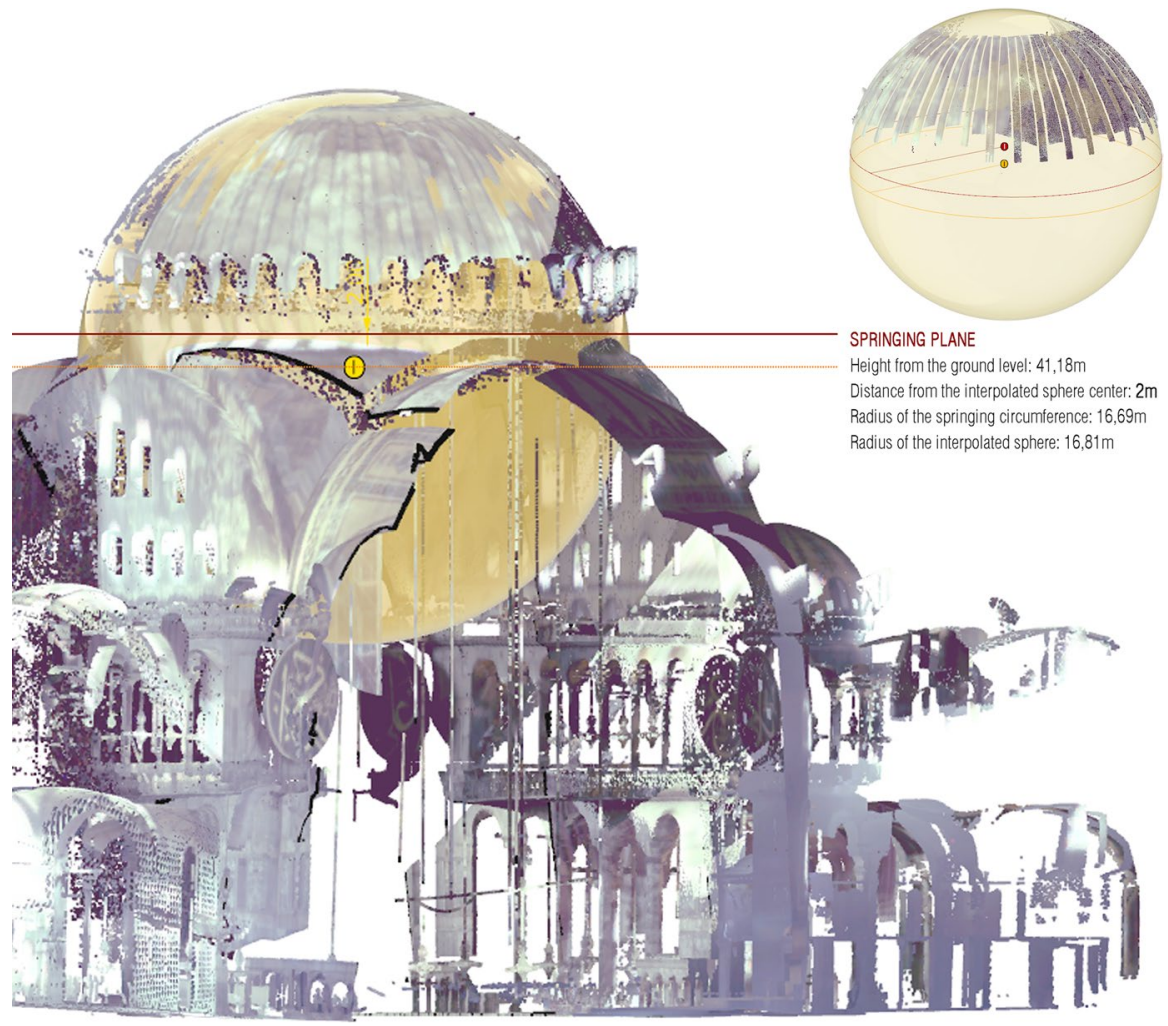

Fig. 11 Hagia Sophia ideal sphere: centre, radius, springing circumference

Fig. 12 Evidence of the deformation leading to an irregular oval shape

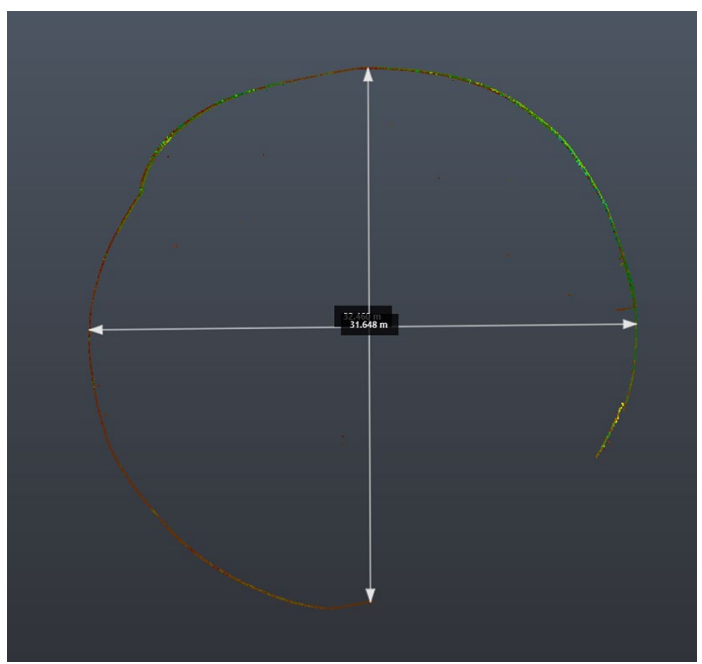



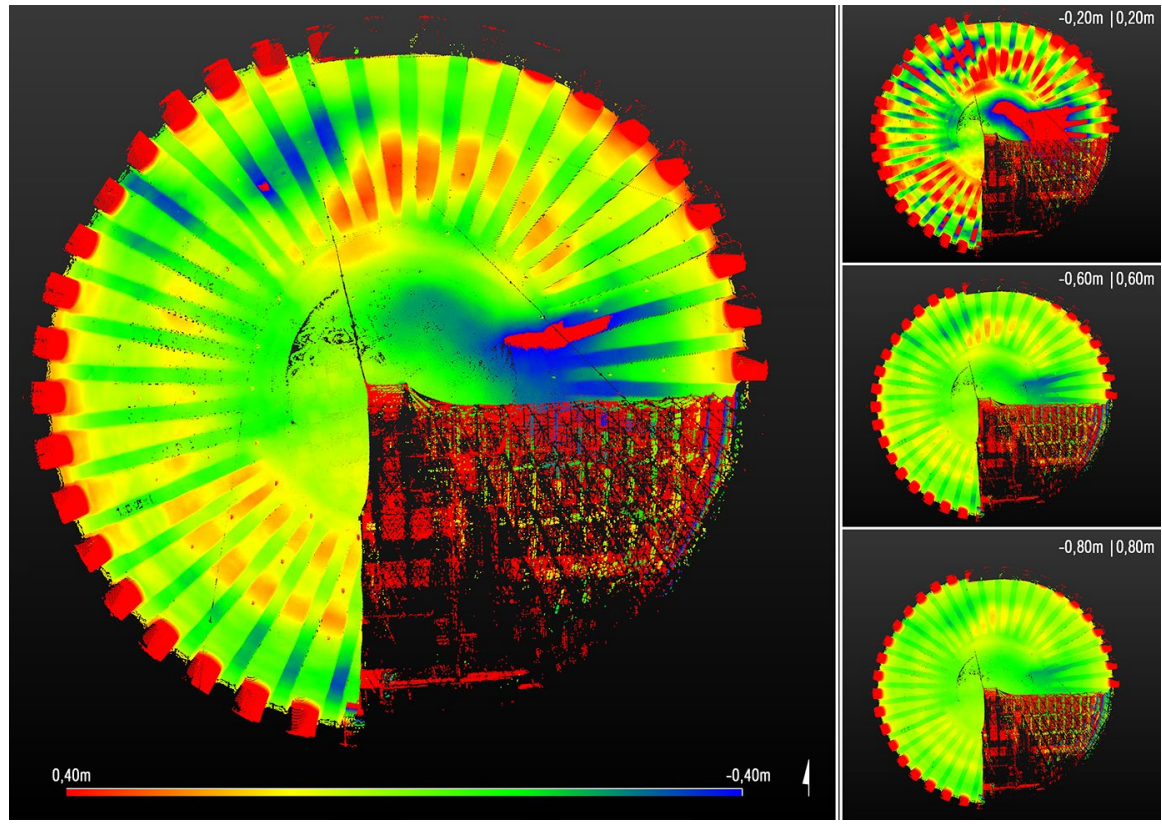

Fig. 13 Deformation of the intrados surface

obviously, on the 3D point cloud we thus built a NURBS surface in which all the deformations discussed above are visible, as well as the current general layout of the intrados. This type of model could help not only further investigations but also suggest to non-specialists the "transformations" suffered by the structure over the centuries (Fig. 14).

\section{Church of St. Carlo ai Catinari}

The Church of San Carlo ai Catinari (Rendina 2000), dedicated to St. Carlo Borromeo, was built during the first decades of the seventeenth century to a design by Rosato Rosati. Owing to some structural problems, Pope Pius IX ordered the restoration of the entire building and especially of its dome (the third largest in Rome after St. Peter's Basilica and Sant'Andrea della Valle), which had heavily suffered from weather damages as well as from the French artillery's bombing of 1849 during the battle against the Repubblica Romana for the control of Rome (Fig. 15). 


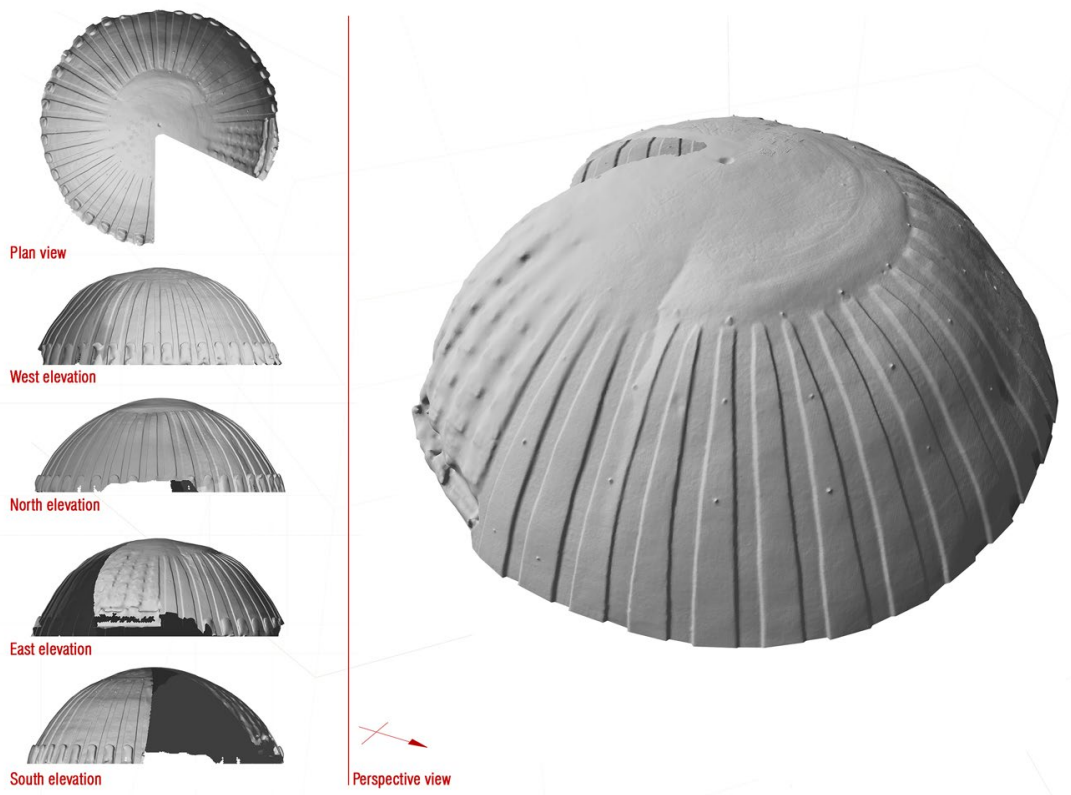

Fig. 14 The superficial 3D model of the dome of Hagia Sophia

The geometry of this dome and of its bearing structures (drum and piers) was first investigated by our team in 2006 and then again in $2018^{8}$ in order to identify the possible damages caused by the earthquakes that had struck the centre of Italy in that period. In contrast to Hagia Sophia, San Carlo's dome and drum did not show any evident deformation or irregular geometry, and appeared instead both regular and homogenous. We could say, then, that our task was to assess the level of this regularity: in other words, we aimed at identifying and measuring all the superficial deformations and misalignments revealed by our 3D capturing systems.

Our reference dataset was again the general point cloud, while our ideal shape for benchmarking was a surface of revolution generated by the rotation of a $2 \mathrm{D}$ curve around a central vertical axis (for the dome) and a cylinder (for the drum). Therefore, we actually organized our workflow so as to define position and geometry of both these elements according to the protocol tested in Hagia Sophia. Thus, the dome and the drum were sectioned with a set of horizontal planes at intervals of $60 \mathrm{~cm}$ (Fig. 16).

\footnotetext{
${ }^{8}$ This work is based on two different 3D point clouds. The first, acquired in 2006 with a Leica HDS 3000 , counts about 70 million points. The second one, captured in 2018 with a FARO 405, is made of more than 500 million points. Both have been coupled with a topographic campaign to ensure the highest control on the quality of the final model. Furthermore, in 2018 a digital photogrammetric surveying took place together with the scanning, adding some 100 million points to the final model, which was also texturized with high resolution images. The average uncertainty of the final numeric model was under $1 \mathrm{~cm}$.
} 

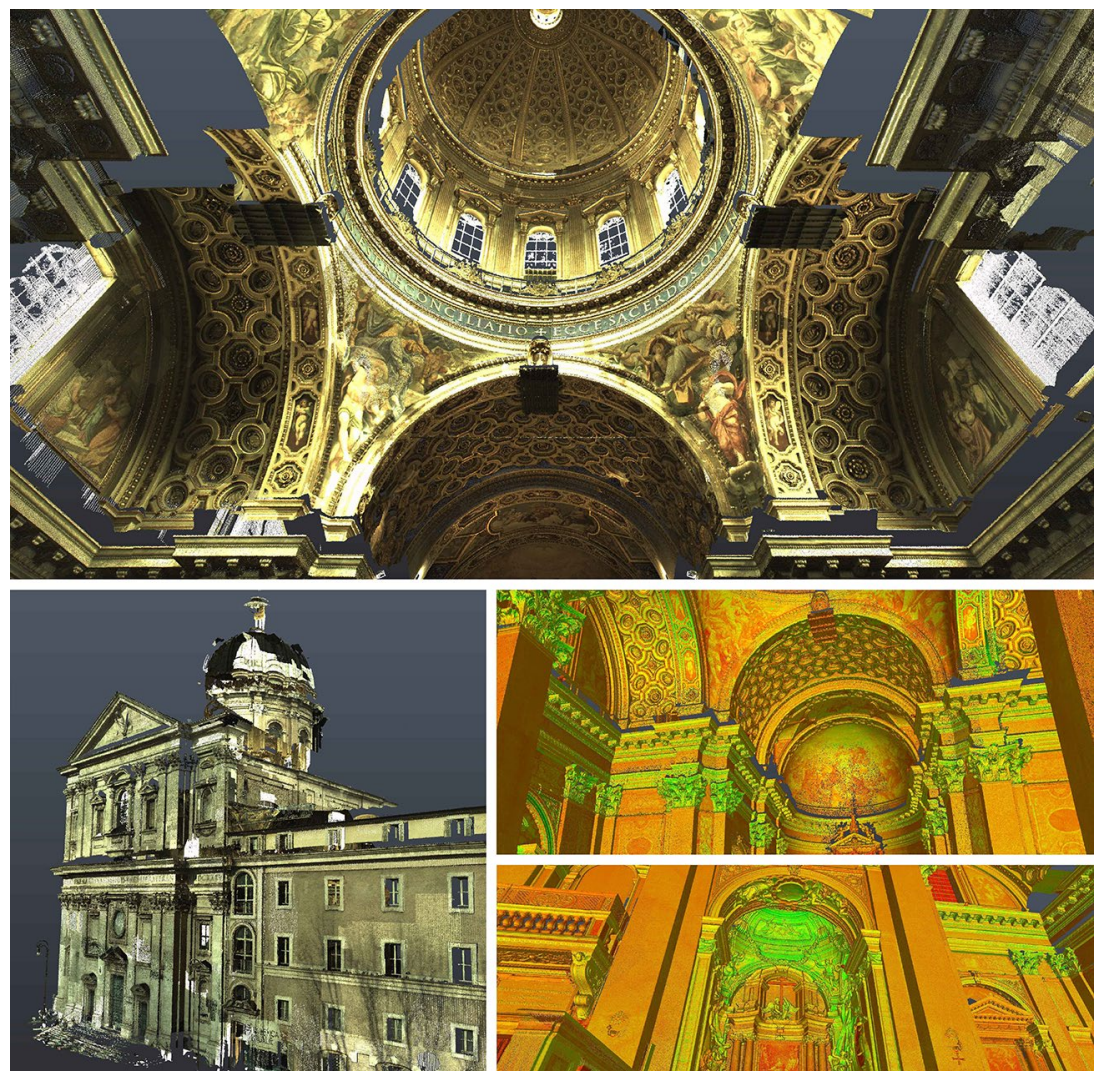

Fig. 15 Texturized point cloud of San Carlo ai Catinari

This slicing operation produced a corresponding number of horizontal profiles representing the progression of surfaces' layout from the base of the drum to the top of the dome. As the decorated intrados is enriched by progressively narrowing deep coffers, we assumed their bottoms as reference profiles for the following constructions of circles. The benchmark geometry of the system (a surface of revolution for the dome, cylinder for the drum) obviously implies that all curves generated would approximate a circle.

Our comparison between the ideal lines and those cutting the bottom of the coffers confirmed this hypothesis, with differences less than $\pm 1 \mathrm{~cm}$ and pretty close to the instrumental level of accuracy $( \pm 0.6 \mathrm{~cm})$. However, we had to assess the vertical alignment of all these circles. Therefore, we first considered the horizontal circumferences at the lantern and springing level of the dome. Having projected the centre of the former onto the latter, we measured the offset between these points, obtaining a value of $2 \mathrm{~cm}$, well under our most optimistic expectations both for our geometric model and the static condition of San Carlo's dome. 

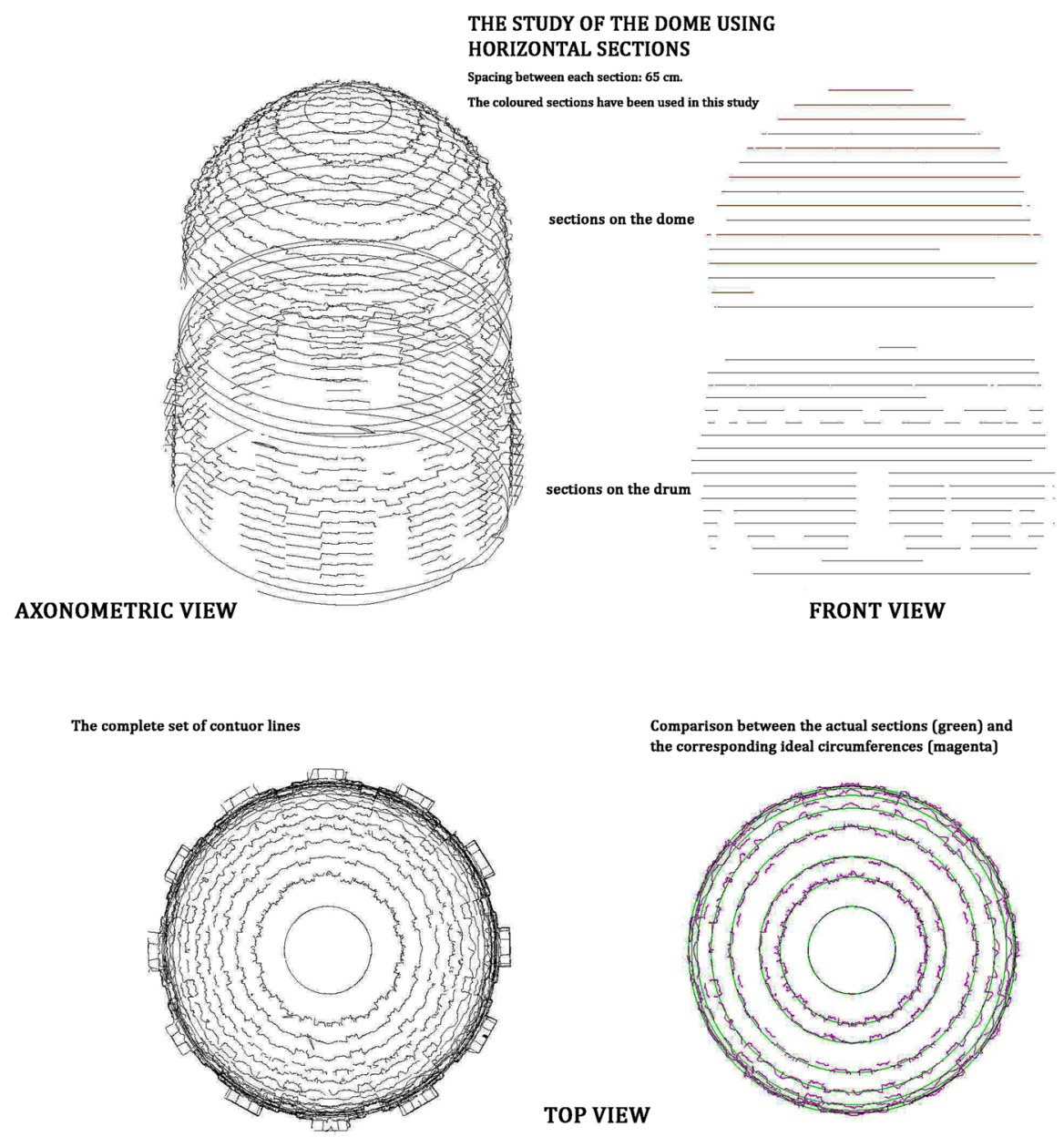

Fig. 16 2D study of the dome and drum of San Carlo: horizontal sectioning

We thus assumed the straight line between the centres of the upper and lower circles as the vertical axis of the dome and the drum and baseline for a family of vertical planes radially slicing the two (Fig. 17). This set of planes eventually generated several vertical profiles of the dome and the drum. They were not exactly the same, obviously, but their differences were not that significant and led us to conclude that the geometry of the structure was still quite conserved in comparison with the original surface of revolution. In particular, the model of the dome showed that it approximates quite closely a spherical surface, except for the portion right under the lantern, which denotes a slight increase in the inclination of the curve, a correction that may have been intended to mitigate the thrust of the structure on the lower drum. The centre of the sphere lies a few centimetres beneath the cornice located at the level of the springing of the dome. 
Fig. 17 2D study of the dome and drum of San Carlo: the vertical sections
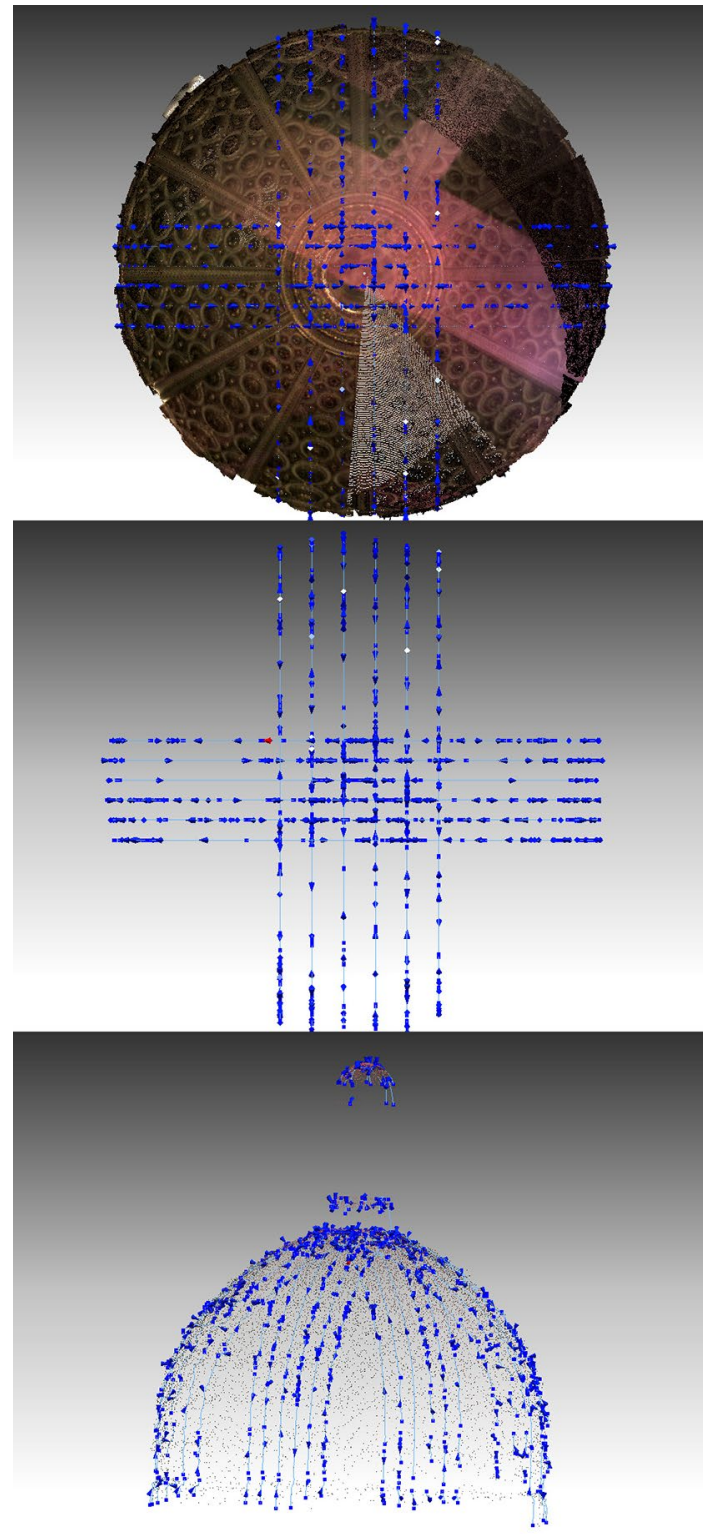

The geometric model resulting from the processing described in the previous section proved very useful for studying the "stability in relation to the shape" of the dome and drum of San Carlo. The reliable reconstruction of some key geometric elements (profiles, axis, position of the centres of curvature, etc.) allowed for an assessment of symmetries, rotations and displacements which, passed on to structural experts, effectively contributed to understanding the current condition of the church. 


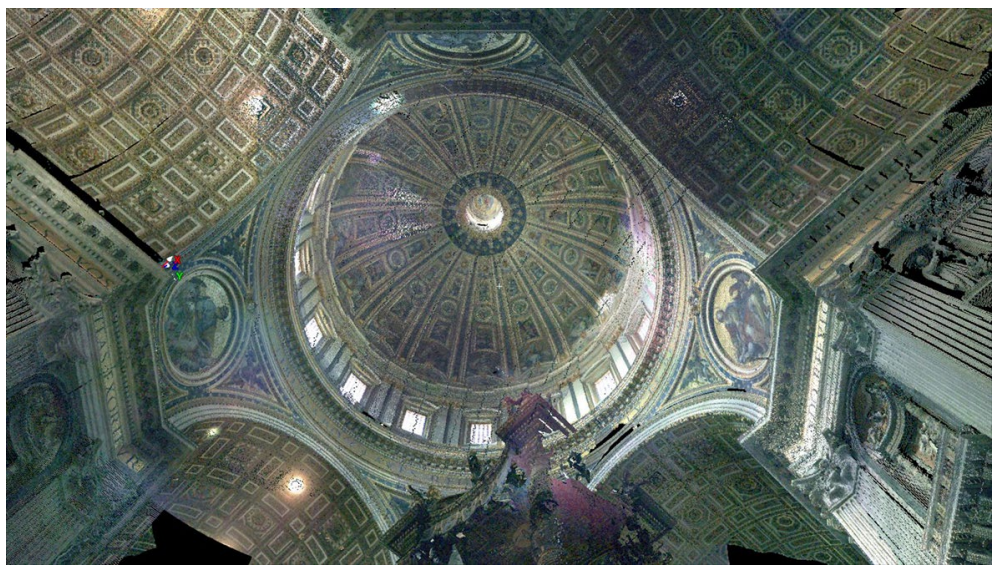

Fig. 18 St. Peter's in the Vatican City: texturized point cloud

\section{St. Peter's Basilica in the Vatican City}

It would be impossible in a few lines to provide even a synthetic description of the long and winding process leading to the greatest dome of Christianity (Di Stefano 1980; Spagnesi 2003). However, it is worth mentioning that the "final" project by Michelangelo simply erased the previous idea of Antonio da Sangallo the Younger, which we can only fully appreciate thanks to the huge wooden model he realized while chief architect of the Fabbrica di San Pietro (1520-1546).

Michelangelo's dome (Fig. 18) is a double-domed structure that takes advantage of the herring-bone brick laying pattern (already used by Brunelleschi for Santa Maria del Fiore) for both its structural features and the consequent reduction of provisional structures such as centrings. After Michelangelo's death in 1564, Giacomo Della Porta and Domenico Fontana continued the construction, reinterpreting in some way the original design. They modified the curvature of the dome and positioned into the masonry the first great iron chains to compensate for the thrust of the shell (Fontana 1694). In the middle of the eighteenth century, a similar intervention was carried out by Poleni in order to respond to the visible cracks crossing the dome and the drum (Rocchi 2009; Carusi 2010).

Many "self-defining" surveys have been published since the construction of the dome. However, in our opinion only the work of Letaroully seems to be consistent enough to be considered an actual survey. With all the limits of a not very refined procedure, overlaying our profiles with the drawings of his Édifices de Rome moderne (Letaroully 1840-55), we have found a very good correspondence.

We could say that both Hagia Sophia and San Carlo represented preliminary tests for the challenging task described in the next lines: the study of St. Peter's dome. Despite the different dimensions and nature of the double-dome structure, the approach used for St. Peter was not much different from that used in the first two 


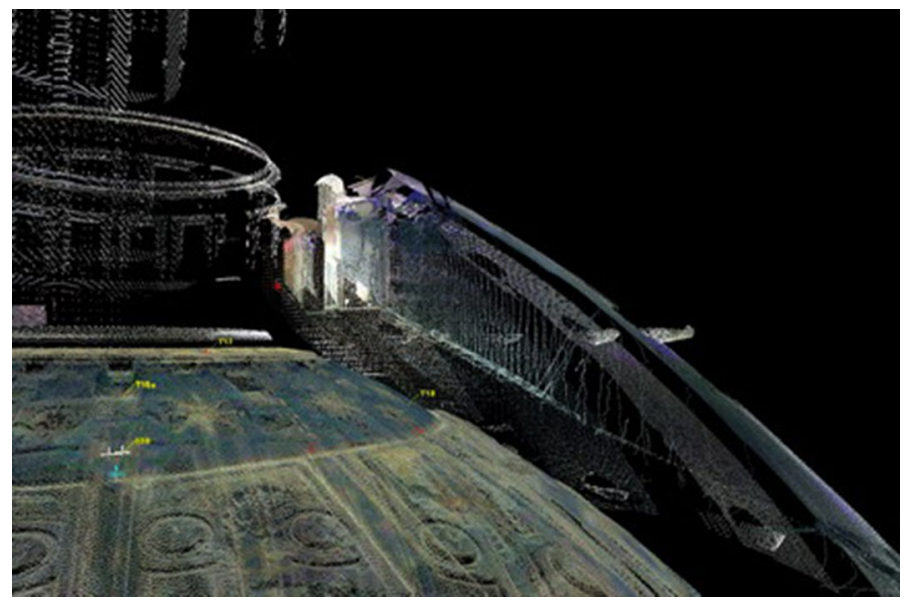

Fig. 19 Portion of the inner surfaces of the double dome

cases: the $3 \mathrm{D}$ point cloud ${ }^{9}$ was sectioned horizontally and vertically, obtaining in the first case "parallels" and in the second "meridians". As in the case of St. Carlo, our aim was to fix the geometry of the system, identify possible deformations, and assess its verticality. When our work was concluded, we were to have passed our model and results to the structural engineers of the group for further investigations. We focused our surveying campaign on the area of the basilica covered by the dome: the four main piers, the drum and finally the inner and outer domes. Several acquisitions were performed at different levels (ground floor, first and second cornices, lantern) and, by a lucky coincidence, ${ }^{10}$ we succeeded in capturing a portion of the inner surfaces of the double dome (Fig. 19).

The first element investigated was the drum starting with two horizontal sections (Fig. 20): the first almost at its top and the second at its base (respectively at $70 \mathrm{~m}$ and $58.35 \mathrm{~m}$ above the floor of the Basilica).

From these curves we could determine the diameter of the cylindrical surface in correspondence of the external walls in which open the great windows of the drum. Despite some minor offsets and two major ones, varying between 23 and $25 \mathrm{~cm}$ along the diagonal aligned with the so-called Pier of Saint Veronica (south-west corner beyond the transept), still these irregularities did not appear relevant enough to contradict the hypothesis that these profiles closely approximated circles.

\footnotetext{
9 The point cloud of about 100 million points was acquired with a Leica HDS 3000 and coupled with a topographic campaign to ensure the highest control on the quality of the final model. Only the 3D cloud captured from the lantern window was not accompanied by a topographic reference, due to time constraints. The average uncertainty of the final numeric model was under $1 \mathrm{~cm}$.

${ }^{10}$ We were able to take advantage of an intervention of maintenance (substitution of a broken pane of glass) to scan the intrados of the dome from the inside of the gap between the inner and outer domes, thus allowing the common registration of both set of points.
} 
Fig. $202 \mathrm{D}$ study of the drum of St. Peter: horizontal sectioning

\section{The study of the drum}

Comparison between the actual shape and the ideal circumference
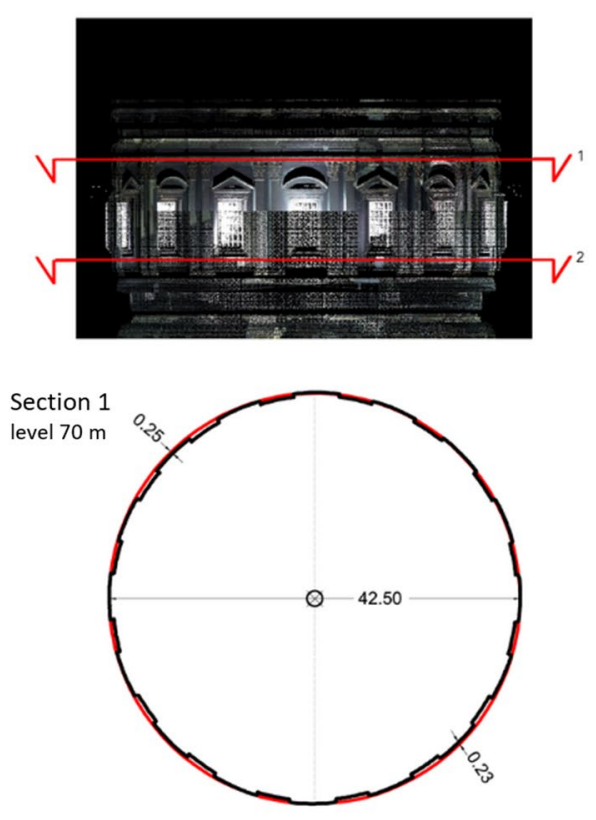

Section 2

level $58,35 \mathrm{~m}$

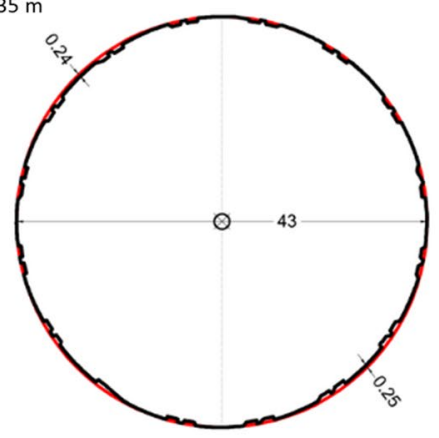

In this framework, the lower diameter (or, if you like, the width of the drum at the level of its springing) measures $43.00 \mathrm{~m}$, decreasing to $42.50 \mathrm{~m}$ at the opposite end. There is thus a slight outwards tapering of the drum at its bottom, probably due to a well-known settlement of its foundations.

The study of the dome surface proceeded according to the workflow already presented in the previous sections: seven horizontal sections were generated in this case (between $77.50 \mathrm{~m}$ and $98.00 \mathrm{~m}$ above the ground floor level) and compared with the corresponding "ideal" circumferences. However, for better understanding, we chose on this occasion to consider two circles for each level: an inner one (shown 


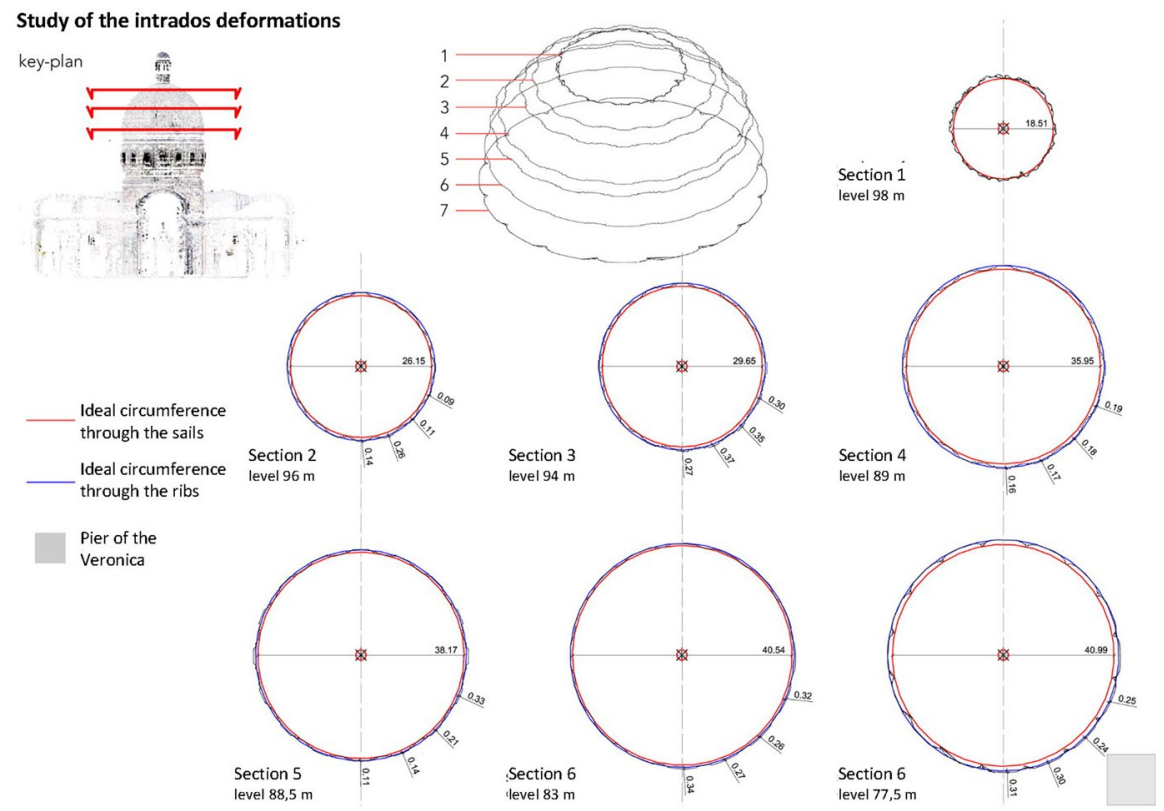

Fig. 21 2D study of the dome of St. Peter: horizontal sectioning

in red in the figures) constructed through the ribs and one more external (shown in blue) passing instead for the bottom of the coffers (Fig. 21).

As for the drum, also in this case we generally registered offsets spanning from a few centimetres to a maximum of $20 \mathrm{~cm}$, always on the outer section. The only exception is the curve drawn at $94 \mathrm{~m}$, where we measured again the highest offset value $(37 \mathrm{~cm})$ right above the Pier of Saint Veronica. However, considering the long and complex chaining interventions on the dome and the rich decorations applied to the intrados, in our opinion these values do not affect the overall geometry of the curves. The step after this focused on the horizontality of the main structures, namely cornices (first and second) and the base of the lantern: in this case the differences we found were consistently under $5 \mathrm{~cm}$.

All the previous constructions led to the tracing of the vertical axis of the surface of revolution that represents our ideal model of the dome (as in San Carlo). The sectioning of the point cloud with a family of radial vertical planes generated a set of meridian profiles, one for each rib and one for each wedged portion. Furthermore, for the part "in between" the domes that we had the chance to capture, these curves were complemented by other two profiles lying respectively on the extrados of the inner dome and on the intrados of the outer one (Fig. 22).

The study of all these lines revealed that they closely approximate circular arcs, thus suggesting a precise $3 \mathrm{D}$ positioning of their centres.

Further analysis dealt with the profile of the entire dome. We chose then two pairs of curves that, cut on the wedged surface, lay on the same vertical plane and 


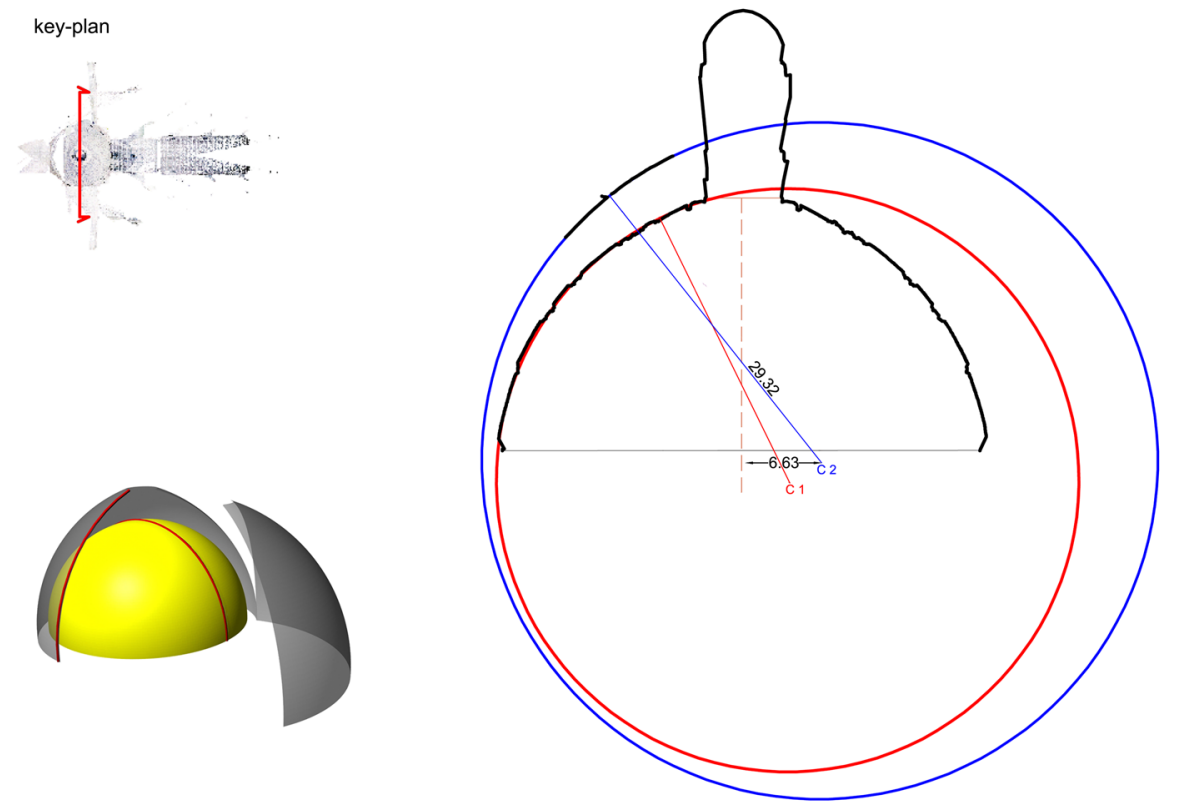

Fig. 22 The circles considered in order to understand the difference between the actual and the ideal circumferences

were aligned with two opposite piers. These compose two perpendicular sections of the entire dome and reveal that the diameters of these diagonal profiles of the inner dome differ only by some $15 \mathrm{~cm}$, always in correspondence with the Pier of St. Veronica (Fig. 23). It is interesting to note that the centres of the profiles lay below the springing line and were offset by $5.35 \mathrm{~m}$ with respect to the vertical axis of the dome (Fig. 24). Similar analysis have regarded the extrados of the inner dome and the intrados of the outer one (Fig. 25).

The 3D modelling phase completed our work also in this case. Taking into account the overall regularity of the geometry, we started by modelling one section of the dome between two ribs. In contrast to Hagia Sophia, in this case we had to distinguish the architectural elements (ribs, cornices, arches, etc.) from the decorative ones (statues, stuccos, etc.). For the former we used a geometric modelling, namely a constructive approach in which all elements were modelled directly using NURBS generative primitives and tools (Fig. 26). For the latter, instead, due to their lack of any geometric footprint, we chose instead to "simply" interpolate the point cloud into a mesh surface (Fig. 27).

\section{Conclusions}

Domes are thorny subjects indeed but the technologies we can use nowadays certainly have radically changed the approach to this problem. Nevertheless, the 3D capturing systems (accurate, fast and massive) provide data that have very 
The study of the profile

Sections in correspondence of two perpendicular planes

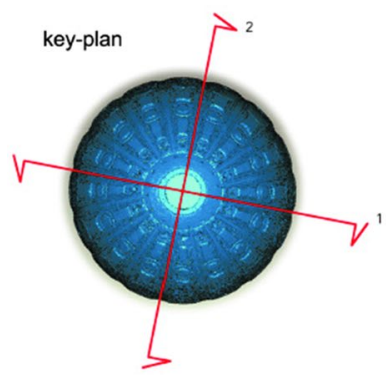

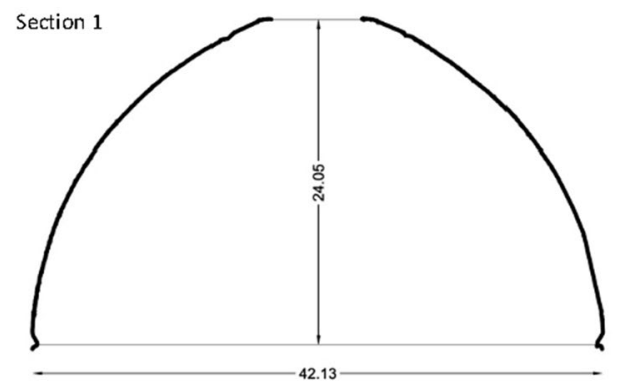

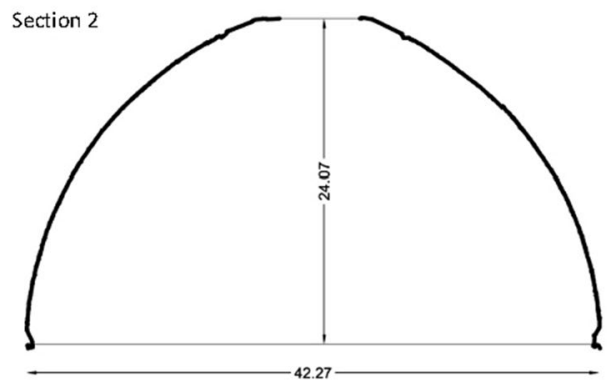

Fig. 23 2D study of the dome of St. Peter: sections through the ribs
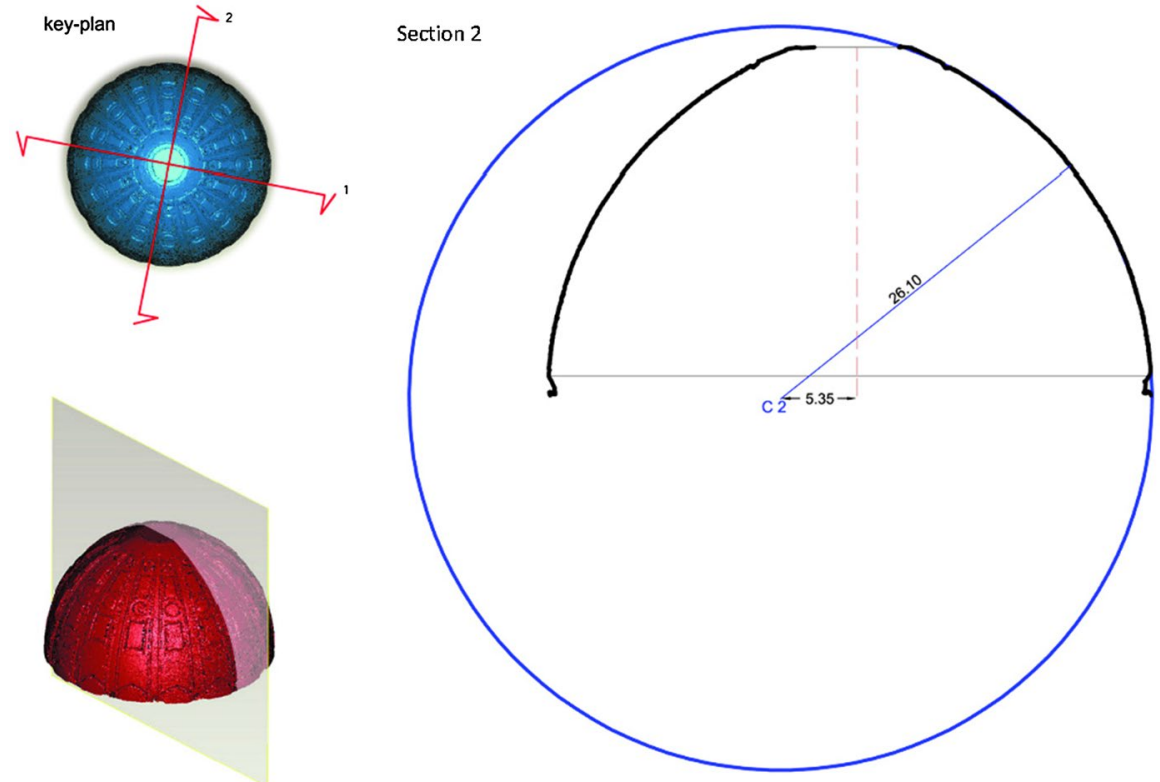

Fig. 24 2D study of the dome of St. Peter: radial profiles 
Fig. $252 \mathrm{D}$ study of the dome of St. Peter: offset of the centres of the extrados of the inner dome and the intrados of the outer one

Fig. 26 3D study of the dome of St. Peter: reconstruction of the intrados
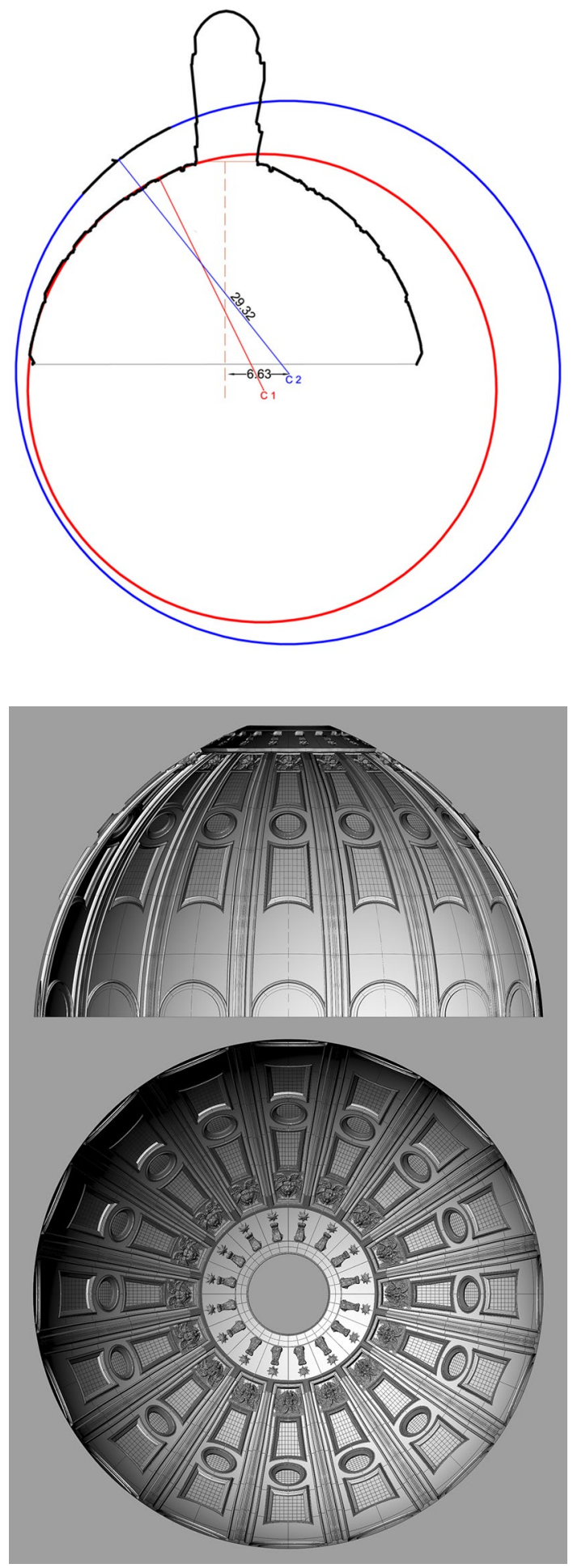


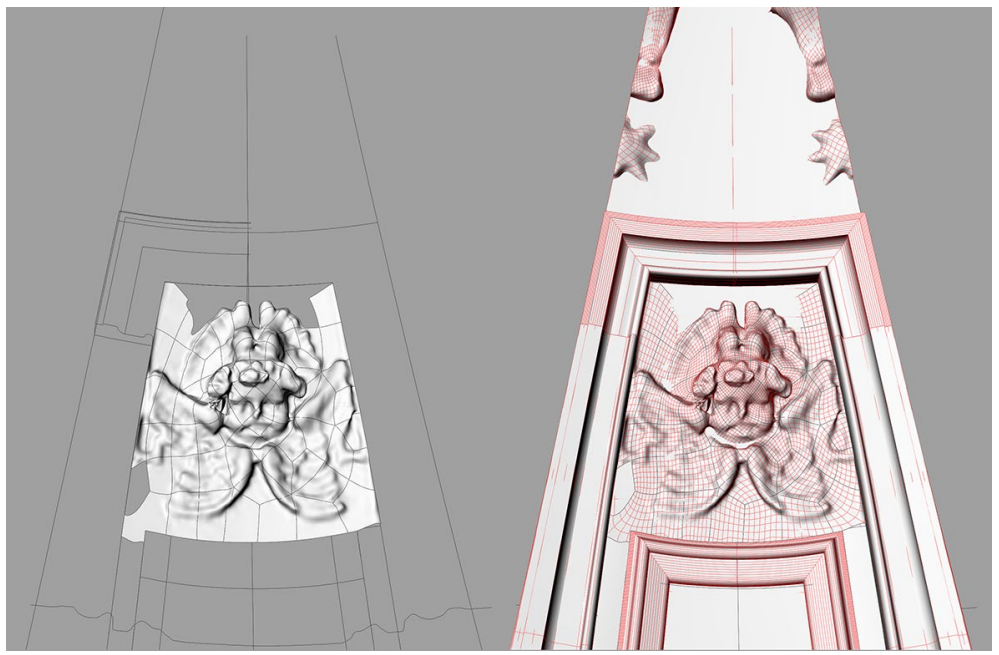

Fig. 27 3D study of the dome of St. Peter: model of the decorative elements

little intelligence inside and represent only the first step of that complex workflow which transforms data into information thanks to a process of selection and interpretation. This is a high-end ability presently reserved to human beings, but which could, in perspective, be extended and taught to some automatic systems too. However, many of the secrets domes have so far concealed can be revealed thanks to these systems, also effectively contributing to their conservation. The more deeply this task is rooted in the scientific method, the better the results will be. It is hoped that the work presented in this paper is able to outline a replicable operative protocol in the study of domes that could guide scholars and even professionals through this difficult activity. In this framework, the three cases illustrated would represent the necessary tests for our protocol or, in a more optimistic vision, some "good practice" in the study of domes. However, we must not give the impression that our study is the first to investigate the metric and geometric features of the three domes presented in this paper. On the contrary, we must compare our conclusions with a vast body of literature with different level of concordance.

With regard to Hagia Sophia, there is an actual correspondence between the 2D geometry presented by Emerson and Van Nice (1943), Mainstone (1988), Hikada and Satō (2004) and ours. Instead, very different is the 3D side of the study, where instead the results are novel in comparison with the earlier works, and also represent an evolution of our previous study (Bianchini and Paolini 2003). San Carlo ai Catinari, for reasons we have not been able to clarify, has been much less studied and our survey appears to be the first systematic one carried out at least in the last 100 years. Instead, for the dome of St. Peter's we perhaps have too much literature but, again, very little data to refer to: the majority of published works are based on partial measuring and local surveys without any systematic reference. The only exception seems to be the work of Letaroully, which, in our opinion, might be the 
result of a systematic campaign. In this case too, then, our work could be considered somehow unprecedented for the technology used and for the analyses carried out. In any case it has been the first to geometrically connect the inner and outer domes.

Acknowledgements The results presented in this paper can be considered as the most recent product of an almost 20-year-long activity carried out by a research team from the DSDRA—Sapienza University of Rome of which the author is part. In this framework, it is worth mentioning the composition of the different crews and the institutions and people providing their support and help. For the Hagia Sophia project: The DSDRA team: Prof. Mario Docci, Prof. Alfonso Ippolito, Prof. Priscilla Paolini, Arch. Marika Griffo. UNIMED and in particular it's former General Secretary, the late-lamented Prof. Franco Rizzi, and his deputy Roberto Albergoni. The Boğaziçi University of Istanbul (the late-lamented Prof. Gunhan Danisman) and, finally, the Direction of the Hagia Sophia Museum. Prof. Hoffman and Prof. Theocaris from Institut für Kunstgeschichte der Universität Bern for their availability in sharing their data with our team. For the San Carlo ai Catinari project: The DSDRA team: Prof. Mario Docci, Prof. Alfonso Ippolito, Prof. Carlo Inglese, Geom. Marco Di Giovanni, Arch. Martina Attenni, Arch. Marika Griffo. Prof. Paolo Rocchi and his team. For the St. Peter in the Vatican City project: The DSDRA team: Prof. Mario Docci, Prof. Alfonso Ippolito, Prof. Priscilla Paolini, Arch. Kostantin Brandenburg, Geom Marco Di Giovanni. Prof. Paolo Rocchi and his team. The Veneranda Fabbrica di San Pietro and in particular Mons. Angelo Comastri, Arch. Luca Virgilio, Dr. Pietro Zander. All images in this paper are by the author.

Funding Open access funding provided by Università degli Studi di Roma La Sapienza within the CRUICARE Agreement.

Open Access This article is licensed under a Creative Commons Attribution 4.0 International License, which permits use, sharing, adaptation, distribution and reproduction in any medium or format, as long as you give appropriate credit to the original author(s) and the source, provide a link to the Creative Commons licence, and indicate if changes were made. The images or other third party material in this article are included in the article's Creative Commons licence, unless indicated otherwise in a credit line to the material. If material is not included in the article's Creative Commons licence and your intended use is not permitted by statutory regulation or exceeds the permitted use, you will need to obtain permission directly from the copyright holder. To view a copy of this licence, visit http://creativeco mmons.org/licenses/by/4.0/.

\section{References}

Bianchini, Carlo. 2012. Rilievo e metodo scientifico I Survey and scientific method. In: Elogio della teoria. Identità delle discipline del disegno e del rilievo I In praise of theory. The fundamentals of the disciplines of representation and survey (Proceedings, $34^{\circ}$ Convegno internazione dei docent della rappresentazione), 391-400. Rome: Gangemi Editore.

Bianchini, Carlo. 2014. Survey, modeling, interpretation as multidisciplinary components of a Knowledge System. SCIRES-IT-SCIentific RESearch and Information Technology4(1): 15-24.

Bianchini, Carlo and Priscilla Paolini. 2003. Rilievo per il restauro e la messa in sicurezza di Hagia Sophia a Istanbul: prime sperimentazioni. Disegnare idee immagini | Drawing ideas images 26: 20-31.

Bianchini, Carlo and Michele Russo. 2018. Massive 3D acquisition of CH. In: 3rd Digital Heritage International Congress (DigitalHERITAGE) held jointly with 2018 24th International Conference on Virtual Systems \& Multimedia (VSMM 2018), 1-8. https://doi.org/10.1109/ DigitalHeritage.2018.8810069.

Carusi, Marta. 2010. La struttura portante della cupola di Della Porta: 1588-2010. Annali di architettura: Rivista del Centro Internazionale di Studi di Architettura Andrea Palladio di Vicenza 22: 125-150.

Chiavoni, Emanuela. 2018. Rome and Its Domes: Drawing, Art and Architecture. Periodica Polytechnica Architecture 49(1): 72-76. 
Di Stefano, Roberto. 1980. La cupola di San Pietro: storia della costruzione e dei restauri. Naples: Edizioni scientifiche italiane.

Docci, Mario (ed). 1997. Il Disegno di progetto dalle origini al XVIII secolo. Rome: Gangemi.

Docci, Mario. 2003. Hagia Sophia. Analisi del rilevamento interno I The survey of the interior of Hagia Sophia. Disegnare idee immagini | Drawing, Ideas images 26: 32-45.

Docci, Mario, Carlo Bianchini, Alfonso Ippolito. 2011. Papers for a theory of Architectural survey I Contributi per una teoria del rilevamento architettonico. Disegnare Idee Immagini | Drawing ideas images 42: 34-41.

Docci, Mario and Riccardo Migliari. 1992. Scienza della rappresentazione. Rome: La Nuova Italia Scientifica.

Dorffner Lionel, Karl Kraus, Josef Tschannerl, Orhan Altan, Sitki Külür, Gönül Toz. 2000. Hagia Sophia-Photogrammetric record of a world cultural heritage. International Archives of Photogrammetry and Remote Sensing 33(B5/1; PART 5): 172-175.

Emerson, William and Robert L. Van Nice. 1943. Hagia Sophia, Istanbul: Preliminary Report of a Recent Examination of the Structure. American Journal of Archaeology47(4): 403-436.

Fondelli, Mario. 1992. Trattato di fotogrammetria urbana e architettonica. Bari: Laterza.

Fontana, Carlo. 1694. Il Tempio Vaticano. Rome: Giovanni Francesco Buagni.

Gaiani, Marco 2012. Per una revisione critica della teoria del rilievo dopo l'avvento dei mezzi digitali. I Towards a critical rethinking of the theory of surveying following the advent of digital media. In: Elogio della teoria. Identità delle discipline del disegno e del rilievo I In praise of theory. The fundamentals of the disciplines of representation and survey (Proceedings, $34^{\circ}$ Convegno internazione dei docent della rappresentazione), 375-382. Rome: Gangemi Editore, 2012.

Hidaka, Ken'ichirō and Tatsuki Satō (eds.). 2004. Architectural-Structural Survey of Hagia Sophia. Tokyo: Chūō-Kōron Bijutsu Shuppan.

Hoffmann, Volker and Nikolaos Theocharis. 2016. Hagia Sophia 3D. Edition Topoi. https://doi. org/10.17171/2-6.

Inglese, Carlo, Mario Docci, Alfonso Ippolito. 2019. Archaeological Heritage: Representation between Material and Immaterial. In: Analysis, Conservation, and Restoration of Tangible and Intangible Cultural Heritage, eds. Carlo Inglese, Mario Docci, Alfonso Ippolito, 1-22. IGI Global.

Leroy, Charles-François-Antoine. 1845. Traité de Stéréotomie. Paris: Gauthier-Villars.

Letaroully, P. M. 1840-55. Édifices de Rome moderne: ou recueil des palais, maisons, églises, couvents, et autres monuments publics et particuliers les plus remarquables de la ville de Rome, 3 vols. Liége: D. Avanzo.

Mainstone Rowland J. 1988. Hagia Sophia: Architecture, Structure and Liturgy of Justinian's Great Church. London: Thames and Hudson.

Migliari, Riccardo. 2008. Descriptive Geometry in the Era of Computers. In: Abitare Virtuale significa rappresentare, ed. Maurizio Unali, 14-31. Rome: Kappa.

Monge, Gaspard. 1811. Géométrie Descriptive. Paris: Klostermann.

Popper, Karl. 1963. Conjectures and Refutations: The Growth of Scientific Knowledge. London Routledge.

Rendina Claudio. 2000. Le Chiese di Roma. Rome: Newton \& Compton Editori.

Ribichini Luca. 2015. Sant'Ivo alla Sapienza: Faith and Reason I Sant'Ivo alla Sapienza tra Fede e Ragione. Disegnare idee immagini | Drawing ideas images 50: 12-23.

Rocchi, Paolo (ed). 2009. Nuove Ricerche sulla Gran Cupola del Tempio Vaticano. Rome: PreProgetti Editore.

Rondelet, Jean-Baptiste. 1802-1817. Traité théorique et pratique de l'art de bâtir. Paris: Chez l'auteur.

Sanpaolesi, Piero. 1973.Discorso sulla metodologia del restauro dei monumenti. Florence: Editrice Edam.

Sanpaolesi, Piero. 1978. La chiesa di S. Sofia a Costantinopoli. Rome: Officina Edizioni.

Spagnesi, Gianfranco. 2003. Roma: la Basilica di San Pietro, il borgo e la città. Milan: Jaca Book.

Publisher's Note Springer Nature remains neutral with regard to jurisdictional claims in published maps and institutional affiliations. 
Carlo Bianchini After classical studies, Carlo Bianchini graduated in architecture in 1991 at Sapienza Università di Roma. He holds a Ph.D. in Survey and Representation of Built Environment, and is Full Professor (SSD ICAR/17-Disegno) in the Department of History, Representation and Restoration of Architecture (DSDRA) at the Sapienza, and is also currently the Director. A member of the scientific committee of several journals (SCIRES-IT, diségno) and book series, he is presently the editor-inchief of Disegnare, Idee Immagini, an ISI-indexed journal listed in ANVUR's class A. He is member of Herimed Association and deputy president of ASSIRCCO. Since 2007 he has cooperated with the CyArk Foundation in the 500 Challenge Initiative. From 2015 to 2018 he was a member of the Steering Committee of the Unione Italiana Disegno (UID). Author of more than 100 scientific works, his research focuses on the documentation, management and promotion of Cultural Heritage (tangible, intangible), on survey and 2D/3D modelling and, most recently, on virtual museums and H-BIM. Since 2002 he has been involved in many research projects funded by the UE in the framework of the Euromed Heritage, Tempus, ENPI CBC-MED, INTERREG III and Erasmus+. 